\title{
Investigation of a single room ventilation heat recovery exchanger under frosting conditions: Modeling, experimental validation and operating strategies evaluation
}

\author{
Samuel Gendebien, Antoine Parthoens*, Vincent Lemort \\ University of Liège, Liège, Belgium
}

\section{A R T I C L E I N F O}

Article history:

Received 17 October 2018

Revised 6 December 2018

Accepted 29 December 2018

Available online 8 January 2019

\section{Keywords:}

Ventilation

Air-to-air heat exchanger

Multi-zone model

Frost formation

Defrost strategies

\begin{abstract}
A B S T R A C T
This paper tackles the issue of frost formation in air-to-air heat recovery devices dedicated to single room ventilation by means of both numerical simulations and experimental approaches. In such heat exchangers, it is commonly known that the formation of a frost layer on the surface generates an additional thermal resistance and a flow section reduction, which leads to an overall degradation of the overall unit performance. This paper proposes a three-zone model, considering a dry, a wet and a frost zone, by determining the location of moving boundaries. Each zone is handled independently and the relative proportion of each zone is determined by means of the exchanger wall temperature. Besides this frost model, a defrost model is also envisaged. Once validated with experimental data collected on a U-flow-type heat exchanger, the developed model is used to implement different strategies to reduce or prevent frost formation in the exchanger. Based on three different criteria, these strategies are compared with each other to evaluate their benefits and drawbacks. The criteria give information on the energy efficiency of the ventilation, on the air renewal quality and on the pressure balance between the inside and the outside of the building.
\end{abstract}

(C) 2019 Elsevier B.V. All rights reserved.

\section{Introduction}

\subsection{Context}

In 2016 in the European Union, households accounted for 25.4\% of the final energy consumption [8]. New and refurbished buildings are showing an increase in their insulation and airtightness, in order to prevent both heat loss and outside air infiltration. However, the indoor air quality must also be ensured. For these reasons, the part of the building consumption related to ventilation is going to increase [30]. To reduce the impact of ventilation on the global building consumption, mechanical ventilation with a heat recovery system is now recognized as efficient [15]. The most widespread configuration is a centralized system involving a single heat exchanger and a duct network for the whole building. However, other solutions exist. One that is gaining interest is a single room ventilation system with devices split among different rooms of a building (Gendebien et al. [14], Designing an air-to-air heat exchanger dedicated to single room ventilation with heat recovery, 2018). Each

\footnotetext{
* Corresponding author.

E-mail addresses: sgendebien@uliege.be (S. Gendebien), a.parthoens@uliege.be (A. Parthoens), v.lemort@uliege.be (V. Lemort).
}

unit has its own set of fans and an air-to-air heat exchanger. The heat from the hot stale air is transferred to the cold fresh air that is injected inside the building. While cooling down, if the stale air temperature drops beneath the dew point, condensation may occur. In the most severe conditions, typically when the outdoor temperature is below $-5{ }^{\circ} \mathrm{C}$ [5], frost may appear. Frost formation can be a major problem in heat exchangers. Under certain conditions, so-called frosting conditions, a frost layer can form on the heat exchanger surfaces. This frost layer leads to a reduction of the cross-section area. Obviously, this reduction then generates an increase in the pressure drop through the heat exchanger and thus an increase in the electrical power delivered to the fans [9]. If the electrical power delivered to the fans remains constant, the air flow rate flowing through the heat exchanger decreases [6], which can lead to unbalanced flow rates. In extreme cases, the frost layer can create a full blockage of air flow passages [35]. Frost layer also corresponds to an additional thermal resistance that affects the exchanged heat transfer rate between the two air streams [10]. As a consequence, overall energy performance will be affected by the presence of frost inside the heat exchanger. Justo Alonso et al. [20] showed that, depending on the exchanger type in the ventilation system, it could be more or less subject to frost in cold climates. 


\begin{tabular}{|c|c|}
\hline \multicolumn{2}{|c|}{ Nomenclature } \\
\hline \multicolumn{2}{|c|}{ Symbols } \\
\hline$A$ & cross section, $\mathrm{m}^{2}$ \\
\hline$A U$ & global heat transfer coefficient, $\mathrm{W} / \mathrm{K}$ \\
\hline$\dot{\boldsymbol{C}}$ & heat capacity rate, $\mathrm{W} / \mathrm{K}$ \\
\hline$c p$ & specific heat capacity, $\mathrm{J} / \mathrm{kg} / \mathrm{K}$ \\
\hline$D_{h}$ & hydraulic diameter, $\mathrm{m}$ \\
\hline$f^{n}$ & friction factor \\
\hline$h$ & specific enthalpy, J/kg \\
\hline$L$ & length of the exchanger, $m$ \\
\hline$\dot{M}$ & mass flow rate, $\mathrm{kg} / \mathrm{s}$ \\
\hline$M$ & mass, kg \\
\hline $\mathrm{Nu}$ & Nusselt number \\
\hline$P$ & pressure, Pa or perimeter, $\mathrm{m}$ \\
\hline$\dot{\boldsymbol{Q}}$ & heat transfer rate, $\mathrm{W}$ \\
\hline$R$ & height of the exchanger, $m$ \\
\hline $\operatorname{Re}$ & Reynolds number \\
\hline RH & relative humidity \\
\hline $\mathrm{t}$ & time, $\mathrm{s}$ \\
\hline $\mathrm{T}$ & temperature, ${ }^{\circ} \mathrm{C}, \mathrm{K}$ \\
\hline$\dot{V}$ & volumetric flow rate, $\mathrm{m}^{3} / \mathrm{s}$ \\
\hline$\dot{\boldsymbol{W}}$ & electric power, W \\
\hline W & width of the exchanger, $m$ \\
\hline$x$ & thickness, m \\
\hline \multicolumn{2}{|c|}{ Greek symbols } \\
\hline$\beta$ & corrugation angle, ${ }^{\circ}$ \\
\hline$\Delta$ & difference \\
\hline$\varepsilon$ & efficiency \\
\hline$\Omega$ & energy performance criterion \\
\hline$\lambda$ & width of the corrugation, $m$ \\
\hline$\phi$ & enlargement factor \\
\hline$\varphi_{\text {balance }}$ & pressurization performance criterion \\
\hline $\begin{array}{l}\varphi_{\text {renewal }} \\
\rho\end{array}$ & $\begin{array}{l}\text { air renewal quality criterion } \\
\text { density, } \mathrm{kg} / \mathrm{m}^{3}\end{array}$ \\
\hline \multicolumn{2}{|c|}{ Subscripts and superscripts } \\
\hline c & contact \\
\hline bnd & boundary \\
\hline $\mathrm{dp}$ & dewpoint \\
\hline ex & exhaust \\
\hline hx & heat exchange \\
\hline ind & indoor \\
\hline meas & measured \\
\hline $\bmod$ & model \\
\hline s & surface \\
\hline su & supply \\
\hline $\mathrm{w}$ & wall \\
\hline
\end{tabular}

Fisk et al. [11] experimentally investigated air-to-air heat exchangers under frosting conditions. They did not develop a numerical model, though they did quantify the amount of time required to defrost the heat exchanger's core, as well as the decrease in terms of efficiency due to the frost layer. Bantle et al. $[4,2,3]$ experimentally investigated a counter-flow heat exchanger under frosting conditions. They divided their heat exchanger model into two zones (dry and condensing parts) and they presented the first mathematical model for frost in counter-flow plate heat exchangers by using empirical correlations. The same trends were observed in terms of thermal performances but there has been a lack of good agreement between simulation and experimental results, and so a much more complex model is required. Philips et al. [27] also developed a discretized simulation model in order to investigate heat transfer rates under freezing conditions. However, they did not investigate the impact of the frost layer on the hydraulic performance and their model has not been experimentally validated. More recently, Nielsen et al. [25] developed a discretized model in order to only predict the heat transfer rate under frosting conditions. However, they did not take into account either the thermal resistance due to frost layer in their model, or the impact of the frost layer on the hydraulic performances. Even though their model showed good agreement with the measured values, they concluded their studies by stating that more precise measurements are needed for the model validation. Moreover, they also stated that it is necessary to improve the calculation model, especially for the defrosting phase. Recently, Beattie et al. [5] proposed two parallel exchanger cores for ventilation systems in very cold climates. The goal was to have one core operating while the other was in a defrosting phase (or in stand-by), ensuring a constant air renewal. Rafati Nasr et al. [28] reported that important topics such as the effect of frost accumulation on airflow rate have barely been covered in the literature and that the problem of frosting in air-to-air heat exchangers remains unresolved. This shows that the frost problem and, more specifically, the control strategies, are gaining interest.

\subsection{Motivations}

Section 5 discusses various different state-of-the-art frost control strategies. Rafati Nasr et al. [28] showed that some frost control strategies in air-to-air heat exchangers in the frame of ventilation systems can lead to energy savings. However, the proposed method only accounts for heat recovery and air conditioning, and does not consider the fan consumption, which will increase with frost layer thickness. This is a key factor, which will impact the global energetic balance. Furthermore, they did not study other aspects such as air renewal quality. As literature on defrost strategy comparisons is still scarce, the present paper aims to efficiently classify the several frost control strategies by establishing different criteria, based on energy consumption, ventilation quality and pressure balance. The strategies are deduced from a single room ventilation heat exchanger model which has been experimentally validated. This model is an extension of a two-zone model proposed and experimentally validated by Gendebien et al. [13] by adding a new zone dedicated to frost. In the present paper, the model is applied to an exchanger presenting a newly developed geometry. It is able to predict hydraulic performance degradation, in particular by showing the pressure drop evolution without spatial discretization of each zone. Experimental data are used to validate the proposed simulation model of the ventilation heat recovery exchanger in frosting conditions. Jedlikowski et al. [18,19] presented such a three-zone model based on the $\varepsilon$-NTU method, coupling mass and heat transfer under frost conditions. However, a set of equations written for a differential control volume is introduced, leading to a discretization of the heat exchanger. Furthermore, the pressure drop evolutions were not accounted for. This last point, however, is essential regarding frost control strategies, as the major frost issue is precisely these pressure drops.

\subsection{Structure of the paper}

A frost growth model (based on several literary publications) is first presented and validated by comparing the obtained results with the experimental results found in literature. A defrost model is also developed in order to investigate strategies allowing the presence of frost in the heat exchanger (so-called defrost methods). The second part of the paper concerns experimental investigations carried out on a heat recovery exchanger dedicated to single room ventilation. Before investigating the behaviour of the heat exchanger under frosting conditions, the two-zone model (dry and 


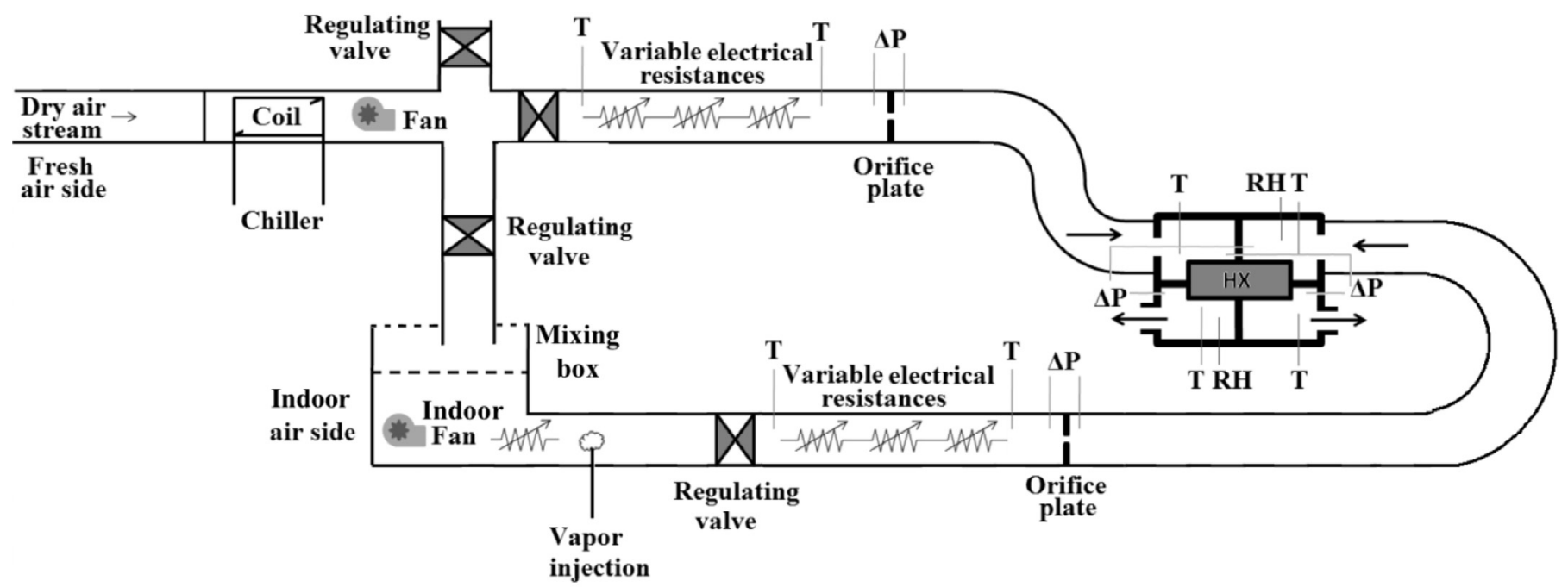

Fig. 1. Schematic description of the test bench.

wet parts) is first checked on this specific heat exchanger presenting a new geometry. Under frosting conditions, pressure drop evolution as well as heat transfer rates are experimentally determined for several supply parameters. Finally, some strategies under frosting conditions are presented and classified depending on whether or not frost is allowed in the heat exchanger. Advantages and drawbacks regarding the implementation of each method are presented, particularly in the case of single room ventilation with heat recovery. Each of these strategies is compared by means of newly defined criteria of overall energy performance, pressure balance and air renewal performance. To the best of the authors' knowledge, only the proposed method permits to determine the overall performance of a specific method. Calculations are carried out using the three-zone model (determination of the heat transfer rates and the pressure drop for each calculation step). This implies knowledge of the fan curve performance, considering that the energy supplied to the fans depends on the flow rate and the pressure drop (and thus on the frost layer whose formation is calculated within a simulation time step of $1 \mathrm{~s}$ ).

\section{Experimental apparatus}

The test-rig that was used for the experimental campaign was described by Gendebien et al. [13]. However, the heat exchanger considered is a new one and the global setup is briefly recalled here.

\subsection{Test bench description}

The test bench is schematically represented in Fig. 1. Fresh air can be cooled down by means of the direct-expansion evaporator of an air-cooled chiller. The fresh air temperature supplied to the heat exchanger can be controlled by means of variable electric resistances.

Indoor air (ambient air) can be cooled down and/or dried by bypassing part of the flow rate exhausting from the coil in a mixing box situated at the inlet of the indoor air fan. As for fresh air, it is possible to control the indoor air temperature by means of variable electrical resistances. Humidity is controlled by the use of electrical steam generators supplied with variable electrical power. The mass flow rates of both fluids (fresh and indoor air) can be adjusted by means of a set of regulating valves and are measured by means of orifice plates, as recommended by ISO 5167 [33]. Differential pressure sensors dedicated to the measurement of air flow

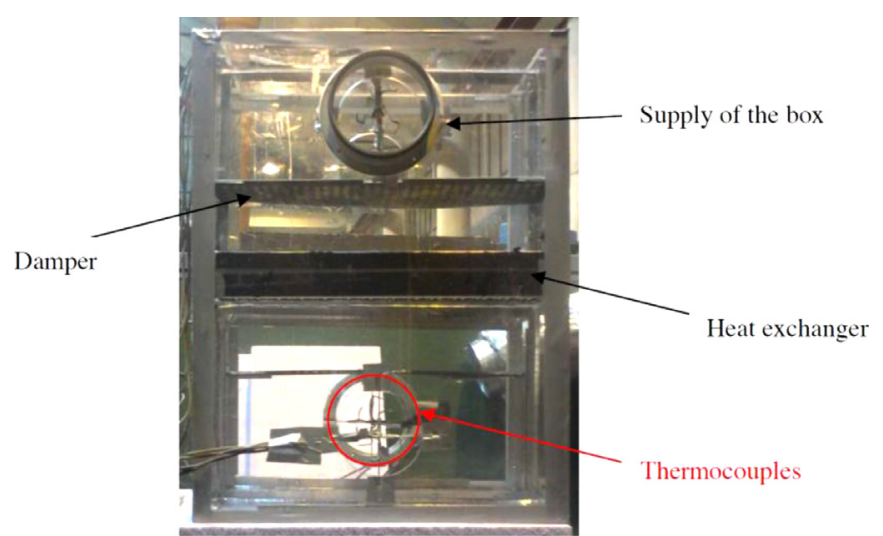

Fig. 2. Plexiglas box.

rates have an accuracy of $\pm 2.5 \mathrm{~Pa}$. Air temperatures are measured with type $\mathrm{T}$ thermocouples with an accuracy of $\pm 0.3 \mathrm{~K}$. In the rest of the paper, the mean supply and exhaust temperatures correspond to the average of two and eight measurements respectively by type $T$ thermocouples. The differential pressure between the inlet and the outlet of the heat exchanger is measured by means of two distinct differential pressure sensors: one dedicated to the lowest air flow rates, with an accuracy of $\pm 1 \mathrm{~Pa}$ and with a fullscale value of $100 \mathrm{~Pa}$, and the other with an accuracy of $\pm 2.5 \mathrm{~Pa}$ and with a full-scale value of $500 \mathrm{~Pa}$. The relative humidities at the inlet and outlet of the indoor exhaust air stream are measured by means of humidity sensors with an accuracy of \pm 2 percentage points.

\subsection{Investigated heat exchanger}

The heat exchanger is located in a box insulated by $30 \mathrm{~mm}$ thick polystyrene in order to reduce heat loss to the ambient. In order to ensure a uniform air flow rate through the heat exchanger, dampers with filters are placed in the box upstream of the heat exchanger, as shown in Fig. 2.

The investigated heat exchanger is a prototype made of polystyrene sheets. It presents a $\mathrm{U}$ flow configuration and was assembled in accordion, as schematically represented in Fig. 4. The central part of the heat exchanger presents corrugations. Geometric characteristics of the tested heat exchanger are given in 


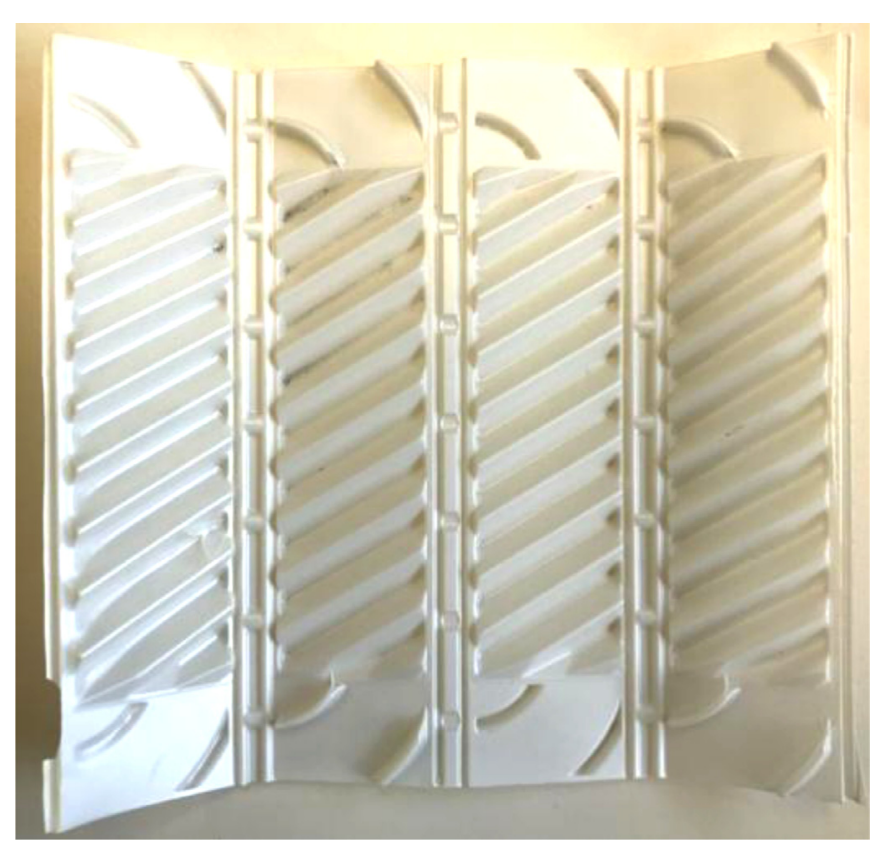

Fig. 3. Corrugations of tested heat exchanger.

Fig. 4 and a picture of the actual corrugations in the heat exchanger is shown in Fig. 3. It is made of synthetic material, and more particularly polystyrene. The major issue with this material is its low thermal conductivity. However, this drawback can be counter-balanced by the high enlargement factors (ratio of the developed length to the protracted length) that can be reached with polystyrene heat exchangers (theoretically $400 \%$ ) compared to traditional plate heat exchangers made of metal (rarely greater than $150 \%$ Ayub et al. [1]).

Corrugation angle definition corresponds to the definition provided by Ayub [1]. Corrugation angle $\beta$ of the central part is equal to $30^{\circ}$ The hydraulic diameter used in the Reynolds number was determined by:

$D_{h}=\frac{4 \cdot A}{P}=\frac{4 \cdot A}{2 \cdot(b+\phi \cdot w)} \simeq \frac{2 \cdot b}{\phi}$

with $b$ and $\phi$ and $w$, respectively the flow channel gap, the enlargement factor and the effective plate width, which is defined by Ayub [1] as the ratio of the developed length to the protracted length.

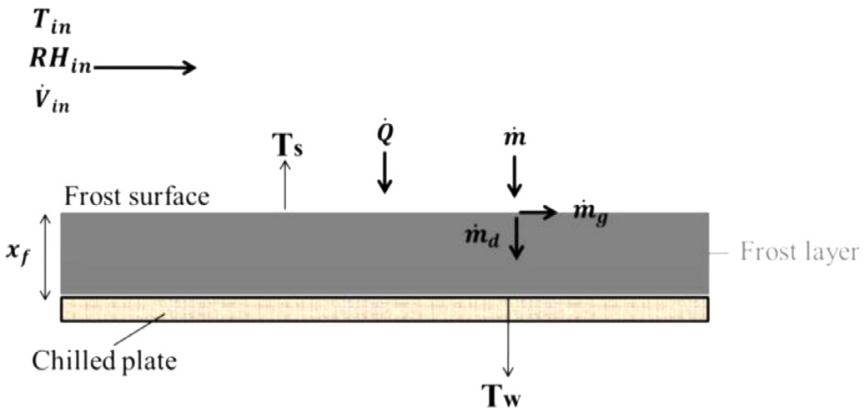

Fig. 5. Air/frost surface interface.

\section{Numerical simulation approach}

\subsection{Frost growth model}

A frost formation model was developed based on different contributions from scientific publications. It was mainly based on the publications of $[7,16,17,21,22,24,32]$. The complete model is described by Gendebien [12]. As shown in Fig. 5, the mass growth depends on two different phenomena. Most of the models consist of dividing the overall mass flow rate $\dot{m}$ into two parts, called the growth $\dot{\boldsymbol{m}}_{\boldsymbol{g}}$ and the densification $\dot{\boldsymbol{m}}_{\boldsymbol{d}}$ mass flow rates. All the equations and correlations that were used are developed in the above-mentioned works. To validate the frost growth model, experimental data presented in the paper of Hermes et al. [17] were used. They observed and quantified the frost formation under several supply air conditions on a temperature-controlled chilled plate of $100 \mathrm{~cm}^{2}$.

Fig. 6 shows the comparison between the model and the experimental data in terms of frost layer evolution for four different wall temperatures. Regarding this figure, results in terms of frost layer thickness evolution are satisfying. Hermes et al. [17] carried out 12 experiments by varying the air relative humidity from $50 \%$ to $80 \%$, the air inlet temperature from 16 to $22{ }^{\circ} \mathrm{C}$ and the plate surface temperature from -5 to $-15^{\circ} \mathrm{C}$. They presented the results in terms of surface temperature $T_{S}\left({ }^{\circ} \mathrm{C}\right)$, mass of frost mass ${ }_{\text {frost }}(\mathrm{g})$, thickness of the frost layer $x_{f}$, which was considered as uniform (mm), and density of the frost $\rho_{f}(\mathrm{~mm})$.

\subsection{Multi-zone heat exchanger model}

To tackle partially wet regimes, Gendebien et al. [13] introduced and successfully validated a two-zone heat exchanger model. It is a moving boundary model based on the classical $\varepsilon$-NTU method. This allows consideration of two distinct parts: a completely dry zone and a completely wet zone.
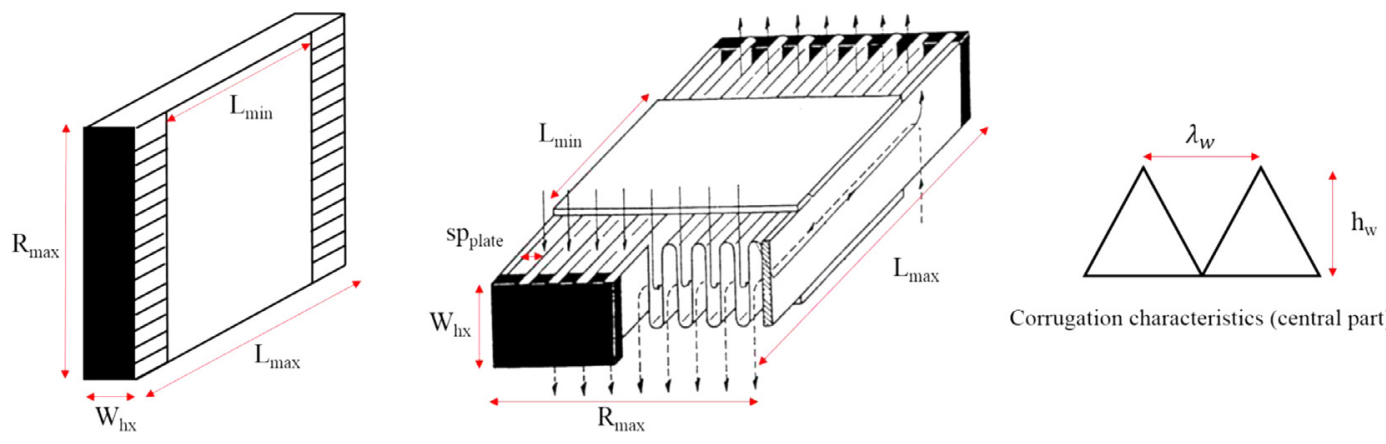

Corrugation characteristics (central part)

Fig. 4. Overall geometric characteristics of the heat exchanger and corrugations of the central part. 


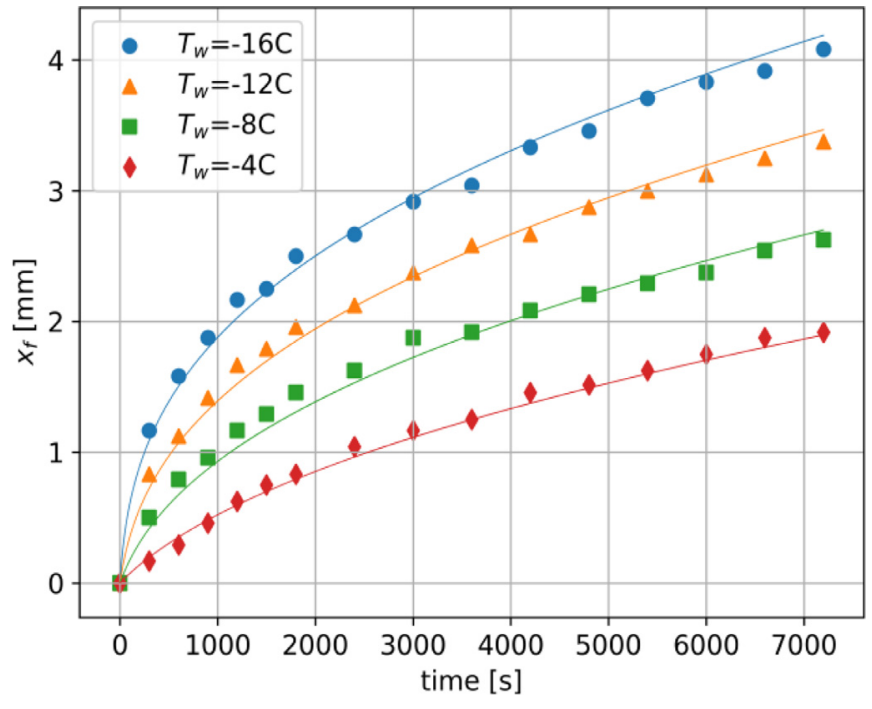

Fig. 6. Frost layer evolution - Model: continuous lines Experimental Data: dots. Inlet temperature $=16^{\circ} \mathrm{C}$, supply; relative humidity $=80 \%$; velocity $=0.7 \mathrm{~m} / \mathrm{s}$.

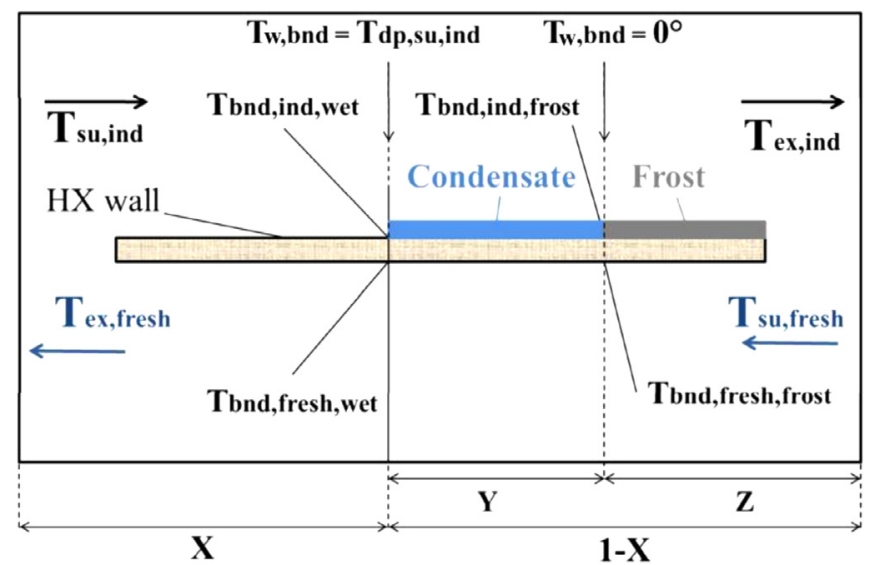

Fig. 7. Schematic representation of a counter-flow heat exchanger presenting three zones (Dry, wet and frost parts).

In the present paper, the goal is to extend the two-zone model to the frost conditions by adding a new zone (i.e. dry, wet and frost zones). The aim is to keep a global model that does not need discretization. A schematic representation of a counter-flow heat exchanger under the three regimes is given in Fig. 7. It can be noticed that the situation is different in cross-flow heat exchangers where the appearance of condensation and frost is a two-dimensional problem, as reported by Mercadier et al. [23]. The boundary condition to determine the frost part corresponds to a wall temperature of $0{ }^{\circ} \mathrm{C}$ and the boundary condition to determine the wet part corresponds to a wall temperature equal to the supply air dewpoint temperature.

\subsection{Defrosting cycle model}

During the defrosting phase, no fresh air was supposed to flow in the heat exchanger. Its modelling was performed in two distinct stages. In the first stage, the available heat from the indoor flow is used to increase the temperature of the frost layer so that it reaches the melting temperature, i.e. $T_{\text {melting }}=0{ }^{\circ} \mathrm{C}$. During the first stage, the frost mass is assumed to be constant and was equal to the mass of frost at the end of the frosting phase. In the second stage, the heat provided allows for the phase change. Consequently, the frost begins to melt. During the phase change, the frost temperature is assumed to be constant and equal to $0{ }^{\circ} \mathrm{C}$. For both phases, the convective heat transfer coefficient on the fresh air side was equal to $7\left[\mathrm{~W} / \mathrm{m}^{2} / \mathrm{K}\right]$, corresponding to natural convection.

The first stage corresponds to a sensible heat transfer. The calculation of the sensible power required the determination of the heat transfer rate exchanged on the indoor and fresh air sides. Heat transfer rates for both sides are respectively given by:

$\dot{\boldsymbol{Q}}_{\text {ind }}=\varepsilon_{\text {ind }} \cdot \dot{\boldsymbol{C}}_{\text {ind }} \cdot\left(\boldsymbol{T}_{\text {su,ind }}-\mathrm{T}_{\mathrm{s}}\right)$

$\dot{\boldsymbol{Q}}_{\text {fresh }}=\boldsymbol{h}_{h, \text { frost }} \cdot \boldsymbol{A} \cdot\left(\boldsymbol{T}_{w}-T_{\text {mean }, \text { fresh }}\right)$

where $\boldsymbol{T}_{\boldsymbol{w}}$ is the wall temperature and $\boldsymbol{T}_{\boldsymbol{s}}$ the frost surface temperature. The effectiveness of the heat exchanger was determined by using correlation dedicated to a semi-isothermal wall. The heat transfer rate delivered to the mass of frost can be approximated by:

$$
\Delta \dot{\boldsymbol{Q}}_{\text {defrost }}=\dot{\boldsymbol{Q}}_{\text {ind }}-\dot{\boldsymbol{Q}}_{\text {fresh }}
$$

The difference in temperature of the frost layer can be determined by the following equation:

$$
\Delta \dot{\boldsymbol{Q}}_{\text {defrost }}=M_{\text {frost }} \cdot \boldsymbol{c}_{\text {frost }} \cdot \frac{\Delta \boldsymbol{T}_{\text {frost }}}{\Delta \boldsymbol{t}}
$$

The thermal capacity of the frost was assumed to be constant and equal to $2060 \mathrm{~J} / \mathrm{kg}$. This expression was used to determine the temperature difference $\Delta T_{\text {frost }}$ for each second, which in turn was used to determine the new temperature of the frost layer $\boldsymbol{T}_{\text {frost }}$. During this stage, the mass of frost was assumed constant in the heat exchanger core. The only varying parameter was the temperature of the frost layer.

The second stage corresponds to a latent heat transfer. The rate at which the mass of the frost varies is given by Nielsen et al (Nielsen et al. [26], Evaluation of a dynamic model for a cold climate counter flow air-to-air heat exchanger, 2008):

$$
\frac{d M_{\text {frost }}}{d t}=\frac{\Delta \dot{\boldsymbol{Q}}_{\text {defrost }}}{\Delta \boldsymbol{h}_{\text {ls }}}
$$

The latent heat of fusion for frost $\Delta \boldsymbol{h}_{\boldsymbol{l s}}$ was assumed to be constant during the whole process and equal to $333 \mathrm{~kJ} / \mathrm{kg}$.

Similarly to the first stage, heat transfer rates were determined on the side of the indoor and fresh air. In this case, the temperature of the frost layer was assumed to be constant and equal to $0{ }^{\circ} \mathrm{C}$. The heat flow rate exchanged by each fluid is given by:

$\dot{\boldsymbol{Q}}_{\text {ind }}=\varepsilon_{\text {ind }} \cdot C_{\text {ind }} \cdot\left(T_{\text {su,ind }}-0\right)$

$\dot{\mathbf{Q}}_{\text {fresh }}=\boldsymbol{h}_{h, \text { frost }} \cdot A \cdot\left(T_{w}-T_{\text {mean }, \text { fresh }}\right)$

Those values were used to determine the $\Delta \boldsymbol{Q}$ required for the change phase (3). The evolution of the mass over time was obtained by using (5). Knowing the mass of frost and thus the frost layer thickness (if assumed to be uniform) at time $t$ it was possible to determine a new hydraulic diameter at each time step. The convective heat transfer coefficient on the side of the indoor air $\boldsymbol{h}_{\boldsymbol{h}, \text { in }}(t)$ could then be computed at time $\boldsymbol{t}$. The thickness of the frost layer is calculated by:

$\boldsymbol{x}_{\text {frost }}=\frac{M_{\text {frost }}(t)}{A \cdot \rho_{\text {frost }}}$

where $\rho_{f}$ was assumed to be constant and equal to the last value calculated during the frosting phase. During the defrosting phase, liquid water resulting from frost melting was supposed to be instantaneously and fully drained out of the heat exchanger. The hydraulic diameter was calculated by taking into account the mass of frost remaining in the heat exchanger and considering a uniform frost layer thickness. 

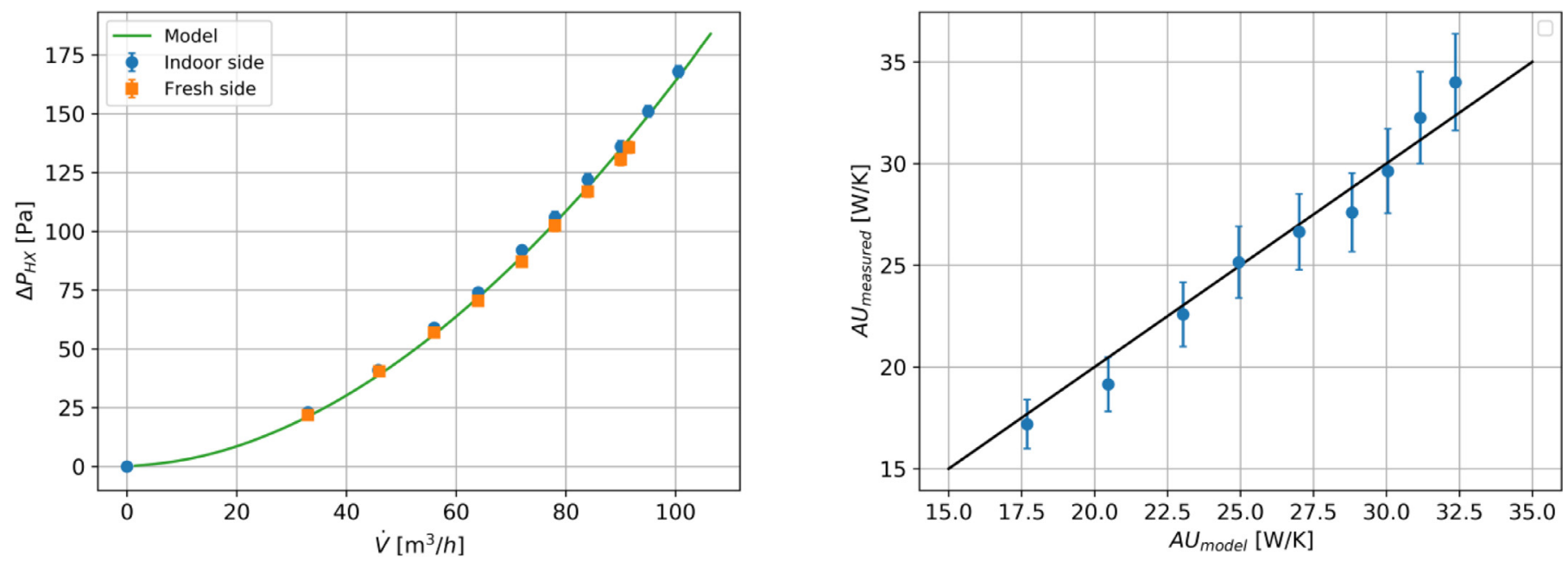

Fig. 8. Hydraulic and thermal model validation in dry regime.

\subsection{Correlations and calibration}

Such models rely on correlations to compute the Nusselt and the friction factor. Concerning the Nusselt number determination, correlation provided by Wanniarachchi et al. [34] had first been used before calibration. This correlation can be applied to heat exchangers presenting a corrugation angle comprised between 20 and $62^{\circ}$. Range of validity concerning the Reynolds number extends from 1 to $10^{4}$. The correlation is given by Eq. (10)

$$
\begin{aligned}
N u= & {\left[\left(3.65 \cdot \beta^{-0.455} \cdot \phi^{0.661} \cdot R e^{0.339}\right)^{3}\right.} \\
& \left.+\left(12.6 \cdot \beta^{-1.142} \cdot \phi^{(1-m)} \cdot \operatorname{Re}^{m}\right)^{3}\right]^{1 / 3} \cdot \operatorname{Pr}^{1 / 3}
\end{aligned}
$$

with:

$m=0.646+0.0011 \cdot \beta$

Correlation for the friction factor determination is also provided by Wanniarachchi et al. [34] and is given in Eq. (12).

$$
\begin{aligned}
f= & 4 \cdot\left[\left(1174 \cdot \beta^{-1.026} \cdot \phi^{2} \cdot R e^{-1}\right)^{3}\right. \\
& \left.+\left(46.6 \cdot \beta^{-1.08} \cdot \phi^{(1+p)} \cdot R e^{-p}\right)^{3}\right]^{1 / 3}
\end{aligned}
$$

with:

$p=0.00426 \cdot \beta+0.0000223 \cdot \beta^{2}$

Given the experimental results in the dry regime shown in Fig. 8, the Nusselt number and the friction factor have been tuned by a factor of 1.1 and 0.9 respectively. The tuning allowed the mean error on the complete set of points to be reduced.

\section{Experimental results and model validation}

As the three-zone model is an extension of the two-zone model, before considering the frost conditions the model was first validated for the dry as well as for the partially wet regimes.

\subsection{Dry regime}

Hydraulic performance was experimentally evaluated on both parts of the heat exchanger. As can be observed in Fig. 8, the difference in terms of pressure drop evolution as a function of flow rate is considered negligible, and the heat exchanger is considered

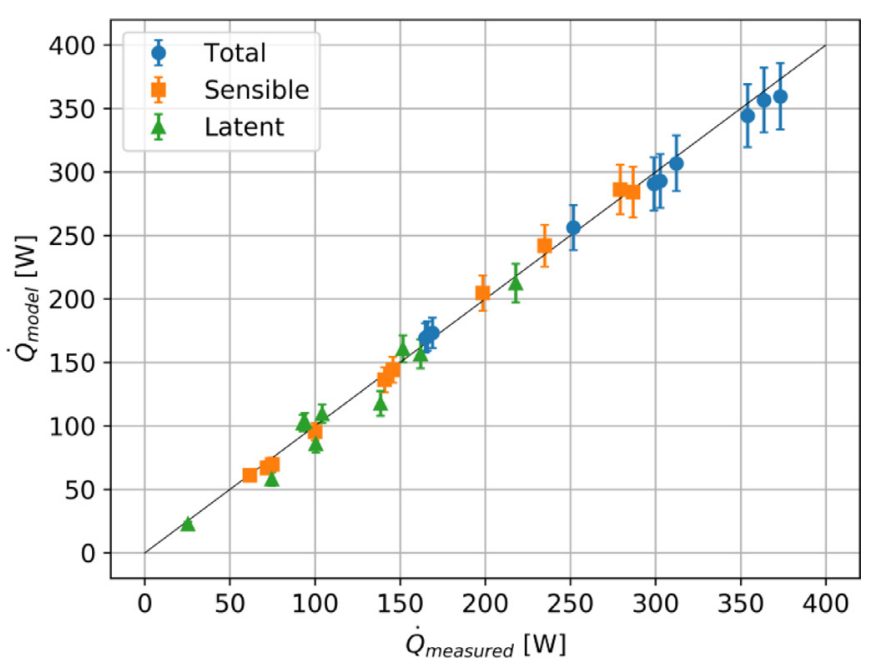

Fig. 9. Comparison between computed and measured heat transfer rates.

symmetric. Furthermore, the experimental data fits well with the model. Two differential pressure sensors are used: one for the difference below $100 \mathrm{~Pa}$ and the other one below $500 \mathrm{~Pa}$. The absolute accuracies of these sensors are $\pm 1 \mathrm{~Pa}$ and $\pm 2.5 \mathrm{~Pa}$ respectively. Concerning the global heat transfer coefficient $A U$, the error bars represent $7 \%$ of the measured value. Considering the uncertainty of the mass flow rate (from 1.5 to $2.2 \%$ according to ISO 5167 (Standard)), the heat transfer rates (from 2.2 to $2.5 \%$ ) and the air pressure drop sensor ( $1 \mathrm{~Pa}$ to $2.5 \mathrm{~Pa}$ depending on the sensor used), the experimental measurements show sufficiently good agreement with the model.

\subsection{Partially wet regime}

The validation of the two-zone (partially wet) model was conducted using the same method as Gendebien et al. [13]. The maximum and minimum temperatures, relative humidity and volumetric flow rates are summed up in Table 2.

The total, sensible and latent heat transfer rates that were measured and computed are compared in Fig. 9 with $7 \%$ error bars. This figure shows that the results computed by the numerical model fit well with the experiment. 
Table 1

Geometric characteristics of the heat exchanger.

\begin{tabular}{lllllllllll}
\hline $\mathrm{R}_{\max }[\mathrm{m}]$ & $\mathrm{W}_{\mathrm{hx}}[\mathrm{m}]$ & $L_{\min }[\mathrm{m}]$ & $L_{\max }[\mathrm{m}]$ & $\lambda_{w}[\mathrm{~m}]$ & $h_{w}[\mathrm{~m}]$ & $\mathrm{n}_{\mathrm{sp}, 1 \text { flow rate }}[-]$ & $\mathrm{sp}_{\mathrm{plate}}[\mathrm{m}]$ & $\beta\left[{ }^{\circ}\right]$ & $D_{h}[\mathrm{~m}]$ & $\phi[-]$ \\
\hline 0.448 & 0.05 & 0.157 & 0.220 & 0.014 & 0.007 & 29 & 0.077 & 30 & 0.059 & 1.41 \\
\hline
\end{tabular}

Table 2

Supply conditions for partially wet experiments.

\begin{tabular}{llllll}
\hline & $\mathrm{T}_{\text {su,fresh }}\left[{ }^{\circ} \mathrm{C}\right]$ & $\mathrm{T}_{\text {su,ind }}\left[{ }^{\circ} \mathrm{C}\right]$ & $\mathrm{RH}_{\text {ind }}[\%]$ & $\dot{M}_{\text {fresh }}[\mathrm{kg} / \mathrm{s}]$ & $\dot{M}_{\text {ind }}[\mathrm{kg} / \mathrm{s}]$ \\
\hline Min & 0.9 & 20.0 & 46.5 & 0.0104 & 0.0180 \\
Max & 5.8 & 25.3 & 83.3 & 0.0270 & 0.0275 \\
\hline
\end{tabular}

Table 3

Supply conditions (experimental conditions).

\begin{tabular}{|c|c|c|c|c|c|c|}
\hline \multirow{2}{*}{$\begin{array}{l}\text { Test } \\
\text { - }\end{array}$} & \multicolumn{3}{|l|}{ Fresh air } & \multicolumn{3}{|c|}{ Indoor air } \\
\hline & $\mathrm{T}_{\mathrm{su}}\left[{ }^{\circ} \mathrm{C}\right]$ & $\mathrm{RH}_{\mathrm{su}}[\%]$ & $\dot{M}[\mathrm{~kg} / \mathrm{s}]$ & $\mathrm{T}_{\mathrm{su}}\left[{ }^{\circ} \mathrm{C}\right]$ & $\mathrm{RH}_{\mathrm{su}}[\%]$ & $\dot{M}[\mathrm{~kg} / \mathrm{s}]$ \\
\hline 1 & -17.7 & n.m. & 0.029 & 19.3 & 40 & 0.029 \\
\hline 2 & -14.9 & n.m. & 0.019 & 19.0 & 35 & 0.019 \\
\hline 3 & -17.7 & n.m. & 0.029 & 19.2 & 64 & 0.029 \\
\hline 4 & -13.9 & n.m. & 0.029 & 20.1 & 44 & 0.019 \\
\hline
\end{tabular}

n.m. = not measured.

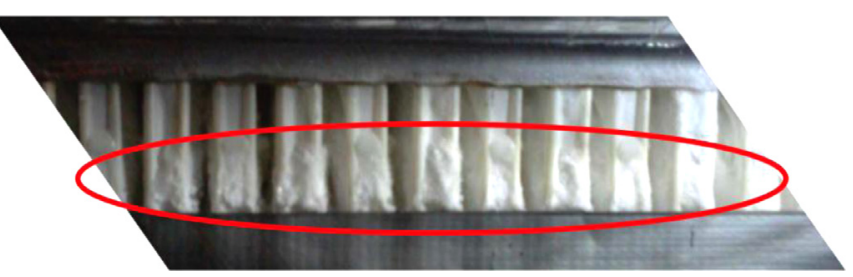

Fig. 10. Visualization of the presence of frost at the exhaust of the heat exchanger.

\subsection{Frost regime}

Performance under frosting conditions was measured for different supply conditions, given in Table 3 . These values are averaged over roughly two hours, depending on the experiment time.

Supply conditions were selected to validate the model in different operating conditions under frosting conditions. All of the tests were carried out with balanced flow rates, except Test 4 , which presents a ratio between fresh and indoor air flow rate different from unity $\frac{\dot{M}_{\text {fresh }}}{\dot{M}_{\text {ind }}}=1.53$.

The presence of frost for each of these tests was visually checked. The transparent Plexiglas box made this observation possible. The frost layer at the exhaust of the heat exchanger can be visualized in Fig. 10.

The model predictions were compared with the experimental data. First, Test 1 was envisaged to analyse a complete frost/defrost cycle. The duration of the experiment was relatively long (more than $10000 \mathrm{~s}$ ). As previously stated, the test presented two phases: the frosting phase and the defrosting phase. For each of these phases, the measured time evolution of the pressure drop was compared with the numerical model. During the defrosting phase, the fresh air flow rate was null, while the indoor air flow rate remained constant. In order to counterbalance the increase of pressure drops due to the presence of the frost layer, the indoor mass flow rate was manually adjusted by means of valves throughout the whole frosting and defrosting phases in order to keep the mass flow rate deviation under $5 \%$.

Concerning the hydraulic performance during the frosting phase, the model seems able to accurately predict the behaviour of

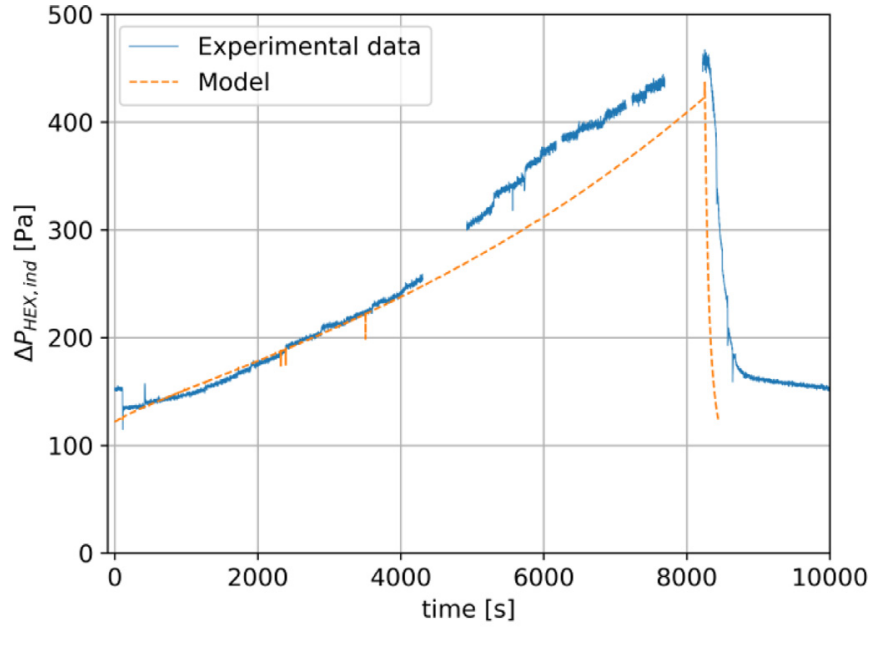

Test 1

Fig. 11. Pressure drop evolution (comparison between model and experimental results, Tests 1).

the heat exchanger under frosting conditions for the first $5000 \mathrm{~s}$. There then follows an under-estimation of the predicted pressure drop. Regarding the hydraulic performance during the defrosting phase, it appears that the model predicts a quicker decrease in the pressure drop compared to the experimental results. This can be explained by the assumption concerning the direct evacuation of the melted frost. In reality, melted frost was not directly removed from the heat exchanger, as it was observed by visual inspection through the Plexiglas box. The absence of measurements during some short time periods corresponds to sensor issues. However, as the trend is clear, it did not imply any problem for the analysis.

Other tests were conducted under different atmospheric conditions. These tests only concern the frosting phase for a duration of $7200 \mathrm{~s}$. This is still a long time in the context of frost control in actual units. The evolution of the measured and computed pressure drops are represented hereafter.

The trends' predictions from the model for Tests 2 and 4 are close to the experimental data. However, Test 3 shows no clear agreement between the model and the measurements. While the model predicts a significant increase in the pressure drop with time, the experiment does not. This could be explained by the supply air conditions. Indeed, the indoor air was much wetter than in the other tests. It means that the wet zone proportion was more significant (73\% for Test 3 against $25 \%$ for Test 1 ). The developed model does not consider the perturbation due to the condensate flushing out of the heat exchanger. During this experiment, it was observed that water condensates came out of the exchanger, taking off some frost. As the model does not take this phenomenon into account, the computed pressure drop is highly overrated.

In practice, the model limitation would not significantly impact the yearly simulations. Indeed, the situation represented in Test 3 is for humid conditions, which is not the typical situation when encountering frosting conditions. The phenomena of flushing out water could be met in dryer conditions, but after a longer freezing time. In practice, the event of a long freezing time will not be acceptable, because it will induce too high a pressure drop. 


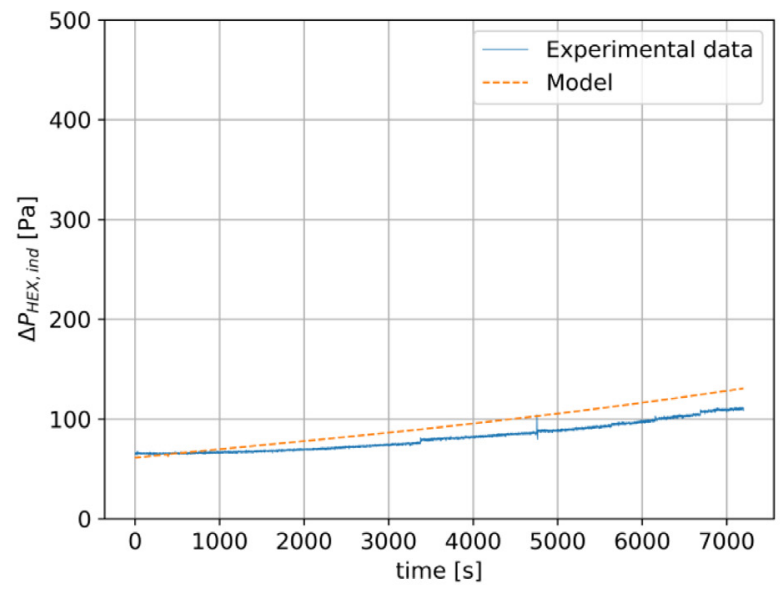

Test 2

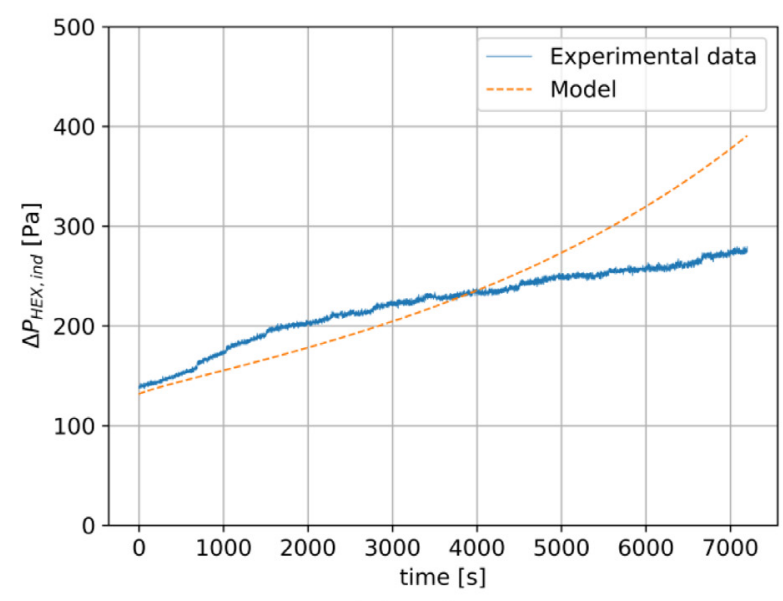

Test 3

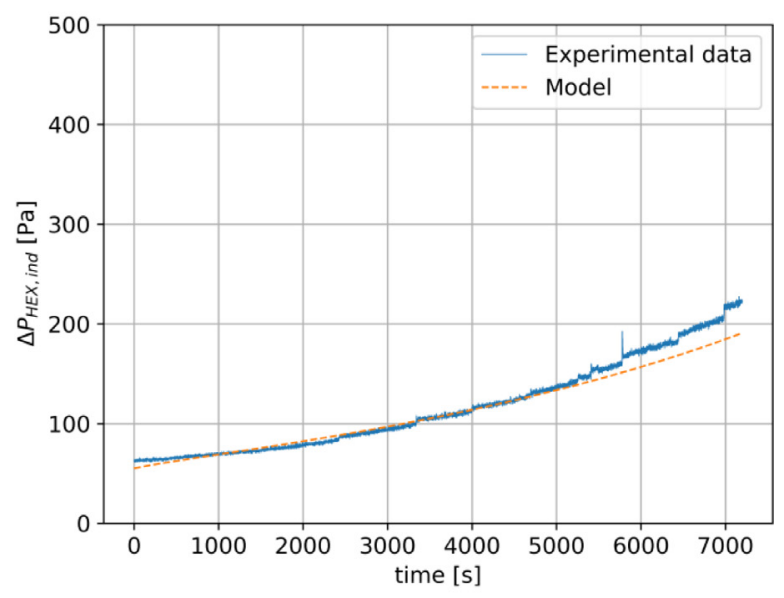

Test 4

Fig. 12. Pressure drop evolution (comparison between model and experimental results, Tests 2,3 and 4).

Hereafter, the thermal performances are analysed for the different experiments.

The trend of the total (i.e. latent + sensible) heat transfer rate seems to fit in each of the different cases. However, even if the thermal resistance caused by frost is taken into account in the model, the decrease of the heat transfer rate due to this latter was more significant in the experimental data than in the model's prediction. Concerning the sensible heat transfer, the model overestimated the results compared to the experimental data. There is a large discrepancy between the model's predictions and the measurements during the first minutes. This can be explained because the thermal inertia was not modelled. The exchanger needs to be in steady state regime before permitting a decent comparison between the experiment and the model. The potential oscillations in the experimental data come from the manual tuning of the mass flow rate, which was intended to keep the mass flow rate as constant as possible as the frost layer grew. These results show a decrease in the global heat transfer rate while the frost layer grows. This could be linked to the increasing thermal resistance that the frost introduces.

It is noted that validating the model in frost conditions was not as straightforward as for the dry or wet conditions. This can be explained by the fact that many physical factors were difficult to control, such as, for instance, the condensates that drained out of the exchanger and took off some of the frost. Furthermore, the supply conditions were not totally stable. The exchanger being light, the model does not take inertia into account. For this reason the inputs were averaged for the numerical simulations. Finally, the experimental setup that was installed for visual inspection induced some interference with the normal operation of the heat exchanger (e.g. ambient heat losses). Despite all these elements, the simulation results were consistent and judged acceptable given the complexity of the phenomena.

\section{Strategies under frosting conditions}

The developed model, which has shown its capability to predict the frost formation evolution, underlined the increase in the pressure drop with frost formation. Besides the electric consumption of the fans, the frost quantity may increase until it blocks the passageways for exhaust air and completely stops the airflow. Several frost control methods are mentioned in scientific literature ([31,27], Nielsen et al. [26], Evaluation of a dynamic model for a cold climate counter flow air-to-air heat exchanger, 2008, [29]). However, there is little literature available on the evaluation performance related to these methods. In the following section, presentation and classification of each technique is proposed and a method of evaluation based on the determination of three different criteria is established to determine the best method to apply. This was carried out using the three-zone dynamic model presented above. Advantages and drawbacks of each method in terms of implementation are also discussed. 


\subsection{Strategies classification}

In order to control the impact of frost, several methods of frost control and defrost strategies are applied to the heat exchangers. These strategies help to avoid or to remove the frost layer on the heat transfer surface of the heat exchangers. There are three categories of frost formation controlling methods: the defrost method [27], the frost control method $[25,31,29]$ and the hybrid method.

The difference between the two first categories of strategies arises from the presence or absence of a frost layer. In the socalled defrost method, a frost layer on the heat transfer surface of the heat exchanger is accepted. This implies cycles of frosting followed by cycles of defrosting. Indeed, this method attempts to remove the frost from the heat transfer surface as soon as a "defined" degradation of heat exchanger performance (e.g. increase in pressure drop) is reached. In the frost control method, no frost on the exchange surface is accepted. The main idea is to prevent any frost formation in the heat exchanger. Several frost control methods exist. For instance, an electrical air heater can be used to raise the fresh air temperature at the inlet of the exchanger. It allows the supply fresh air temperature to be maintained above the frost threshold temperature. Generally, the frost control method starts when a criterion defined by the manufacturer is reached. In most cases, if the outdoor temperature is equal to a threshold temperature then the frost control method starts. Hybrid methods could also be imagined. This would result in a combination of "defrost" and "frost control" methods. Indeed, the presence of a frost layer is accepted but the frost formation is reduced.

\subsection{Defrost methods}

Defrost methods generally consist of a cycle involving two phases: a frosting and a defrosting phase. The frosting phase corresponds to the formation of a frost layer on the heat exchanger surface. The defrosting phase corresponds to the decrease/melting of the frost mass. As an example, a criterion on the pressure drop or on the volumetric flow rate can be imposed. When the criterion is reached, the defrosting phase begins.

For the frosting phase, two options are envisaged. The first imposes a constant indoor flow rate. This means that as the frost layer grows, the pressure drop increases, involving an increase in the electrical power of the indoor fan. The evolution of this power is derived from the fan curve, which can be experimentally deduced. The second option is to keep a constant electric fan power. During the formation of the frost layer, the pressure drop will increase, leading to a decrease in the volume flow rate of indoor air for a given electrical power. These two different approaches should also be used during the defrosting phase.

As suggested by Fig. 13, the defrosting phase can be performed in two ways: either the fresh air fan is simply shut off, or it is shut off and the indoor air is re-circulated. The first strategy [27] is the simplest and most commonly used (Fig. 15). The indoor air is no longer cooled down and the frost layer on the exchange surface begins to melt. Generally, the frosting/defrosting phases correspond to a determined set time period (e.g. $40 \mathrm{~min}$ of frost phase and 5 min of defrost phase) that can be a function of the outdoor temperature. The defrost phase is easily implemented but this method has several drawbacks. The frequency of the frost/defrost cycle can acoustically disturb inhabitants with single room ventilation. Moreover, during the defrost mode, the building is under a negative pressure because the outdoor air fan is shut off while the indoor air fan still runs.

The indoor air recirculation method [27] proposes to block the entrance of the fresh air duct to prevent it from flowing within the exchanger. The indoor air exhaust duct is connected with the supply of the fresh air duct so that the indoor air flows through both ducts. In other words, a recirculation of indoor air is introduced; as a consequence, only the indoor air circulates within the heat exchanger (Fig. 16). The main advantage of this method is that it reduces the defrosting time compared to the previous method. However, the practical implementation is complex, especially for single room ventilation. Furthermore, the ventilation is interrupted and, as with the previous method, the frequency of the frost/defrost cycle can bring acoustic disturbance.

\subsection{Frost control methods}

Four different frost control methods are envisaged in the present paper (Fig. 13):

- The unbalance method (Nielsen et al. [26], Evaluation of a dynamic model for a cold climate counter flow air-to-air heat exchanger, 2008).

- The electric preheating [27].

- The decrease in the effectiveness of the heat exchanger [27].

- The preheating by mixture of indoor air and outdoor air [29].

All these strategies avoid the formation of frost in the heat exchanger. Theoretically, the considered parameter for determining the potential presence of frost is the contact temperature at the exhaust of the heat exchanger $T_{c, e x}$ : frost will not form on the heat exchange surface if this temperature is above $0^{\circ} \mathrm{C}$.

The balance adjustment method (Fig. 17) involves adjusting the volume flow rate of each side to prevent the formation of a frost layer. Unlike the defrost cycle method, this method does not require the complete halting of the fresh air fan. However, it does require the determination of the contact temperature. This temperature can be known directly or be deduced from the outside temperature by means of a control model (use of the "two zones" variable boundary model). The major benefit of this method is its ease of implementation because the fans can be controlled independently, the ventilation is not interrupted, and several strategies can be implemented (i.e. rise of indoor air side flow rate, decrease of fresh air side flow rate or variation of both flow rates). Nevertheless, as the flow rates are unbalanced, the building is depressurized, and if the fresh air flow rate is set at minimum, the indoor air flow rate has to be increased. This can lead to fan noise issues, especially in the case of units placed in bedrooms.

The following technique involves preheating the fresh air before it enters the heat exchanger. Two main techniques exist. On one side are the pre-heating coils, and on the other side the electric heaters. In the framework of this paper, only the second solution is envisaged. It can be achieved by using an electric heater positioned upstream of the heat exchanger (Fig. 18). As long as the space is available, it is easy to implement. This preheating can be done in several stages (use of several resistances) depending on the chosen strategy. In fact, the preheating can be split into two or three stages. The method is initialized when a threshold outdoor temperature is reached within the heat exchanger. The air is pre-heated before entering the exchanger. After this step, the fresh air recovers heat in the recovery device, in the same way as seen in the previous strategies. The use of resistance involves additional electric consumption, decreasing the global performance of the system, but the flows remain balanced and there is no interruption to ventilation.

Another approach is to reduce the effectiveness of the heat exchanger. In order to implement it, some passages of the heat exchanger that allow the passage of the volume flow rate are blocked. Consequently, the effectiveness decreases and the contact temperature of the exchange surface is kept above $0^{\circ} \mathrm{C}$. The main advantage of this method is that ventilation can remain on. Unfortunately, the practical implementation of this method seems 


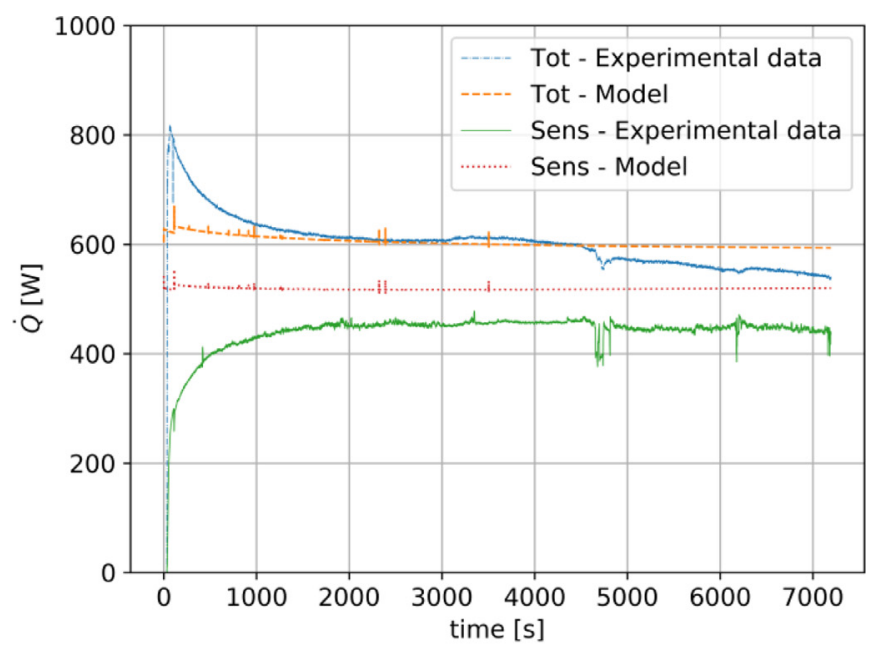

Test 1

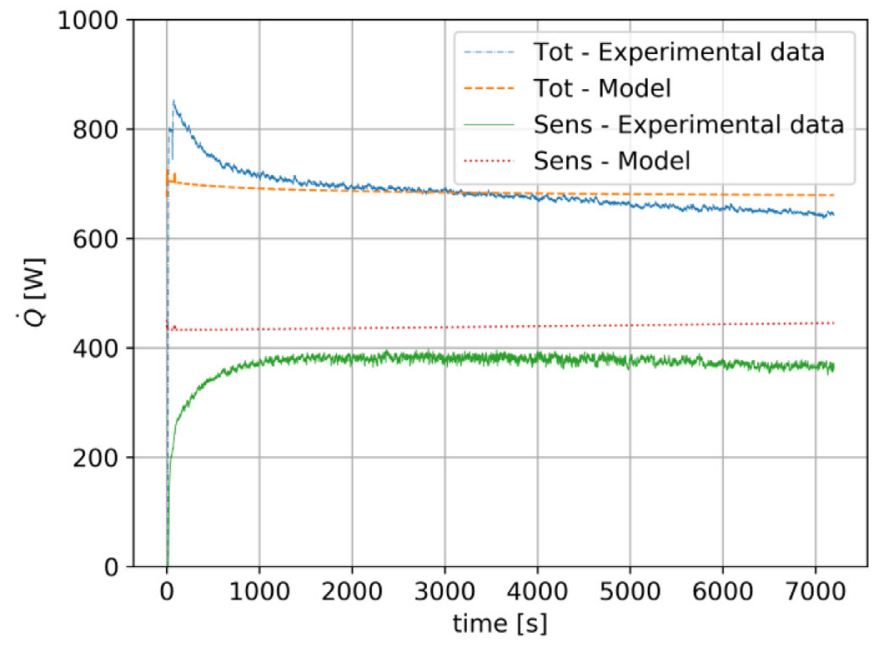

Test 3

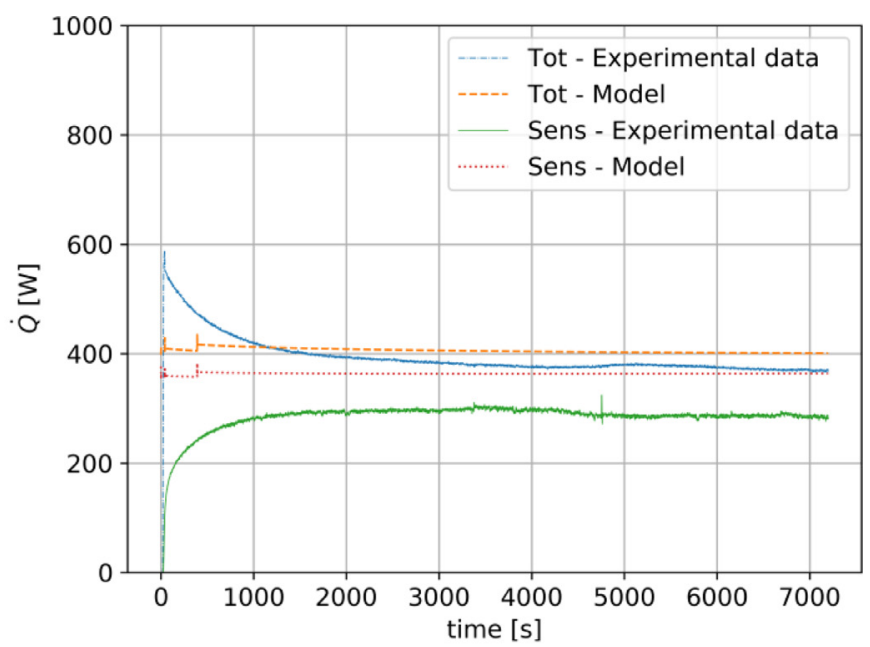

Test 2

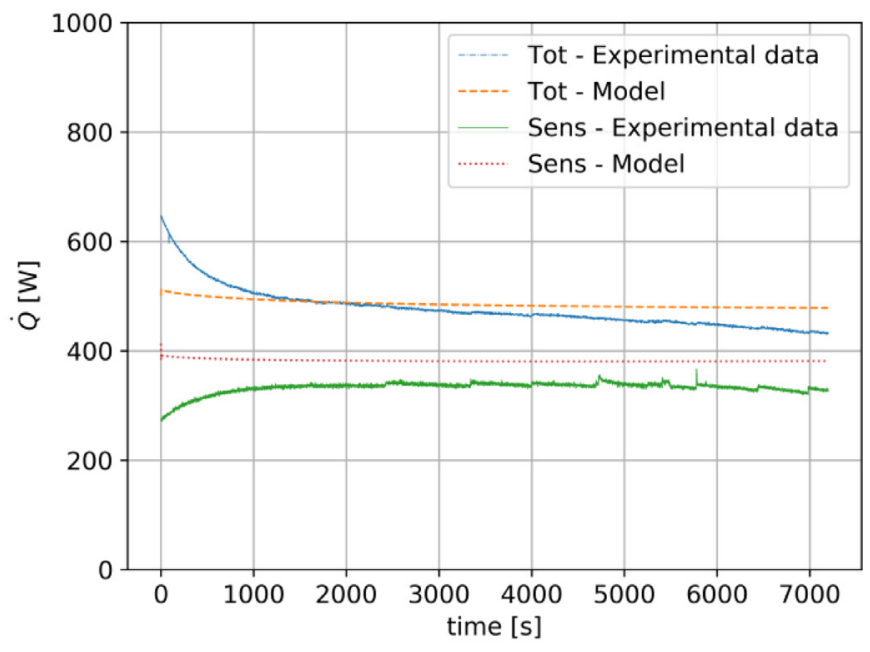

Test 4

Fig. 13. Total and sensible heat transfer rates evolution (comparison between model and experimental results, Tests $1,2,3$ and 4 ).

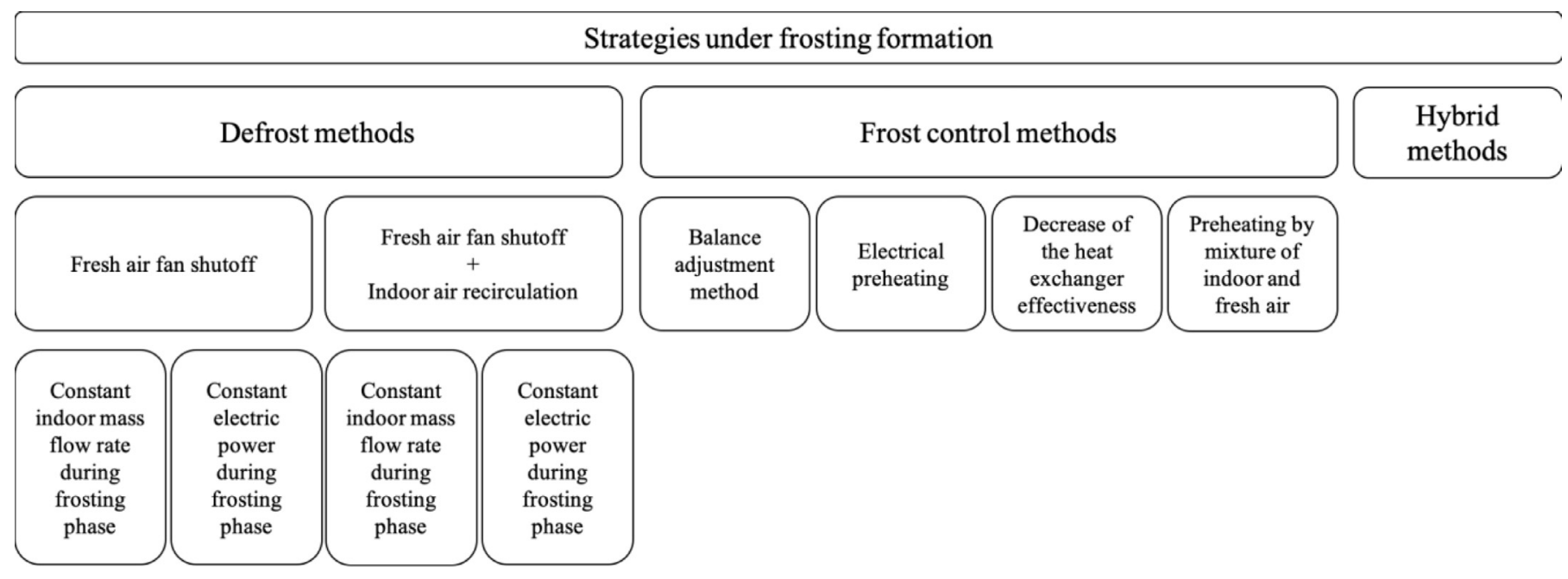

Fig. 14. Strategies under frosting conditions. 


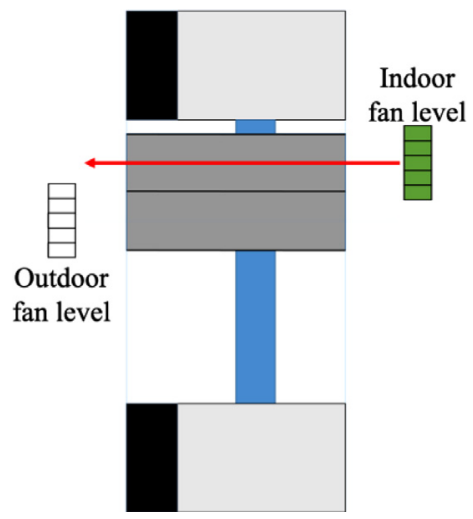

Fig. 15. Schematic representation of supply outdoor air fan shut off (during defrosting period).

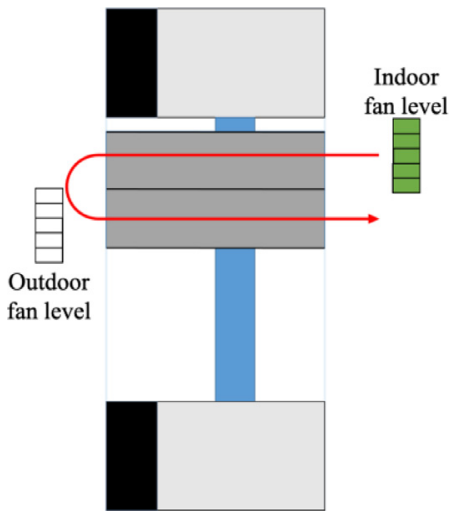

Fig. 16. Schematic representation of an indoor air recirculation method (during defrosting period).

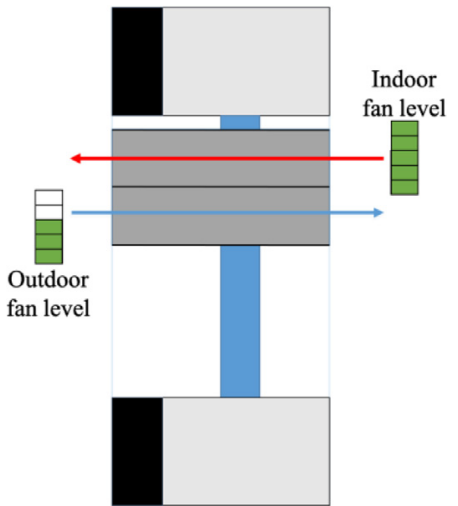

Fig. 17. Schematic representation of the balance adjustment method.

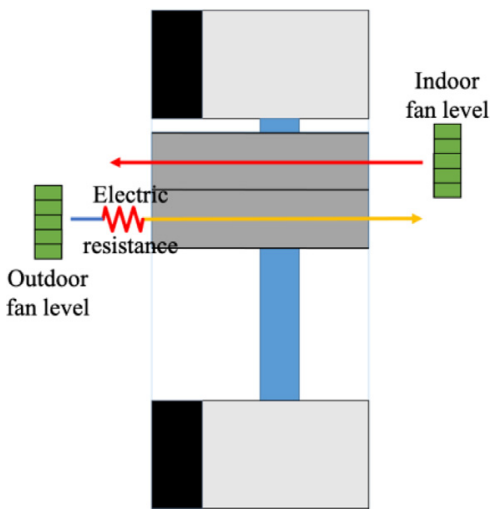

Fig. 18. Schematic representation of the electrical pre-heating method.

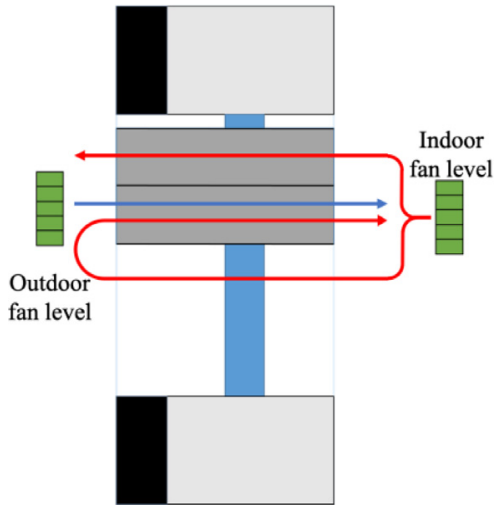

Fig. 19. Schematic representation of the "preheating by mixture" strategy.

quite complicated, especially for devices such as single room ventilation with heat recovery. Furthermore, the heat energy recovered is low and fan consumption is high when blocking a large part of the supplies of the heat exchanger (increase in the pressure drop). This method was not implemented in the framework of this paper.

The last method envisaged is preheating by a mixture of indoor and outdoor air (Fig. 19). This method consists of preheating the fresh air going into the heat exchanger by mixing it with the indoor air. The principle is to derive a part of the indoor air flow rate to the fresh air side heat exchanger supply. It can be achieved by adding a duct/section in direct contact with outdoor air. When the threshold temperature is reached, a valve can be proportionally opened and the mixture can take place. In other operating conditions, the valve remains closed. This leads to a precise control offering several strategies, and to uninterrupted ventilation. However, the practical implementation is difficult. Furthermore, the electrical consumption of both fans increases. The fresh air flow rate after mixture is higher and the indoor air flow rate also increases in order to ensure the derivation of the indoor air for mixing.

\subsection{Criteria of strategy performance: Definitions}

In order to consistently compare the strategies, a criterion of energy performance is required. This criterion is defined as the ratio between the energy recovered and the energy delivered to the fans

$\Omega=\frac{E_{\text {recovered }}}{E_{\text {elec }}}[-]$

with $E_{\text {recovered }}$ and $E_{\text {elec }}$ representing respectively the thermal energy recovered and the electrical energy supplied to the fans in [J].

Some authors, such as Rose et al. [29], preferred to compare some strategies by considering the yearly energy consumed and recovered. They carried out investigations for two different climates (Denmark and Greenland). They multiplied the electrical energy by a factor of 2.5 to convert it into primary energy. In reality, Rose et al. [29] investigated a method involving two heat exchangers in parallel. They performed a combination of the balance adjustment method and the defrosting/frosting cycle. This strategy is impossible to apply to single room ventilation given the restriction on the available volume.

In the framework of this paper, strategies will first be compared by means of Eq. (14). The integration is carried out on a cycle involving a frosting phase of $7200 \mathrm{~s}$ and a defrosting phase whose duration depends on the strategy:

$\Omega_{\text {device }}=\frac{\int \dot{Q}_{\text {recovered }} d \tau}{\int \dot{W}_{\text {elec }} d \tau}$ 


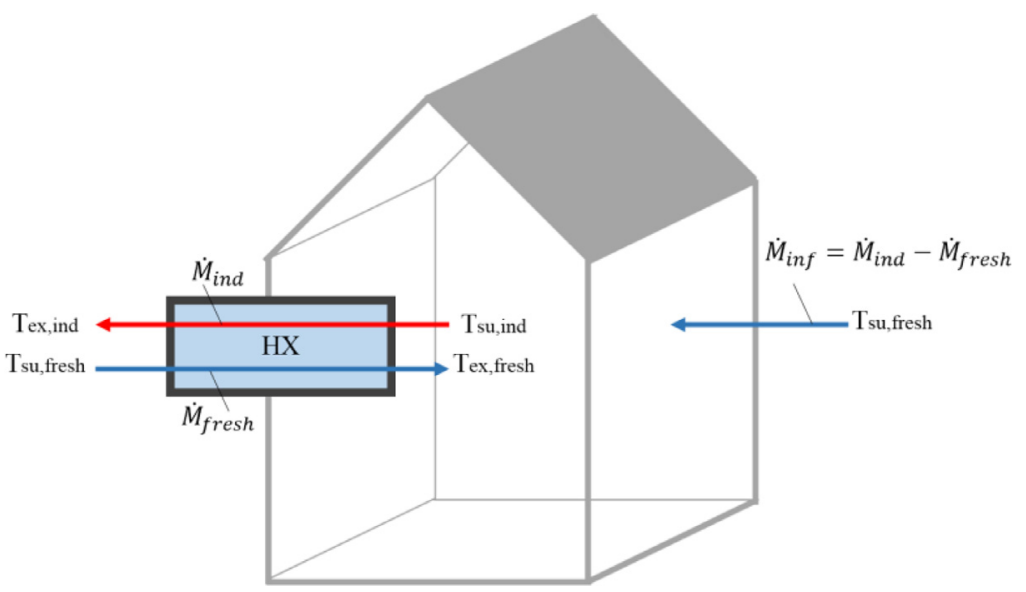

Fig. 20. Infiltration resulting from unbalanced flow rates $\left(\dot{M}_{\text {ind }}>\dot{M}_{\text {fresh }}\right)$.

Table 4

Supply conditions for investigations on frost/defrost strategies.

\begin{tabular}{lllllll}
\hline$\dot{V}_{\text {ind,max }}\left[\mathrm{m}^{3} / \mathrm{h}\right]$ & $\dot{M}_{\text {ind,max }}[\mathrm{kg} / \mathrm{h}]$ & $\dot{V}_{\text {fresh,max }}\left[\mathrm{m}^{3} / \mathrm{h}\right]$ & $\dot{M}_{\text {fresh,max }}[\mathrm{kg} / \mathrm{h}]$ & $T_{\text {su, ind }}\left[{ }^{\circ} \mathrm{C}\right]$ & $T_{\text {su, fresh }}\left[{ }^{\circ} \mathrm{C}\right]$ & $R H_{\text {su, ind }}[-]$ \\
\hline 50 & 59.4 & 44.2 & 59.4 & 18 & -15 & 0.5 \\
\hline
\end{tabular}

with $\dot{Q}_{\text {recovered }}$, the power recovered at each time step in [W]. Knowledge of the fan curve performance (i.e. the required electrical power regarding the imposed pressure drop and the volumetric flow rate) is necessary to deduce $\dot{W}_{\text {elec }}$. If flow rates are unbalanced, it is assumed that the flow rate difference stems from infiltration, as schematically represented in Fig. 19, for a case where the indoor flow rate is higher than the fresh air flow rate.

In this case, the recovered heat rate at each time step is determined by:

$\dot{Q}_{\text {recovered }}=\left(\dot{M}_{\text {fresh }}+\dot{M}_{\text {inf }}\right) \cdot c_{p} \cdot\left(T_{\text {mix }}-T_{\text {su,fresh }}\right)$

with $T_{\text {mix }}$ the temperature resulting from the fictitious mixing of the infiltration and the flow rate flowing through the heat exchanger:

$T_{\text {mix }}=\frac{\dot{M}_{i n f} \cdot c_{p} \cdot T_{s u, f r e s h}+\dot{M}_{\text {fresh }} \cdot c_{p} \cdot T_{e x, f r e s h}}{\dot{M}_{\text {ind }} \cdot c_{p}}$

This relies on the assumption that if there is a lower pressure inside than outside the building, infiltration takes place - either in buildings presenting low airtightness, or when doors or windows are opened in an airtight building.

Two other indicators, $\varphi_{\text {balance }}$ and $\varphi_{\text {renewal }}$, were introduced to characterize the different strategies more acutely.

$\varphi_{\text {balance }}=M_{\text {out }} / M_{\text {in }}$

$\varphi_{\text {renewal }}=M_{\text {fresh }} / M_{\text {fresh,max }}$

$M_{\text {out }}$ and $M_{\text {in }}$ are respectively the mass of air that is extracted from, and supplied to, the room during the whole simulation time. $M_{\text {in }}$ can either be indoor air, fresh air, or a mixture of both, depending on the strategy. $\varphi_{\text {balance }}$ gives an idea of the pressure balance between the indoor and the outdoor. If it is greater than 1 , the building is over-pressurized and thus subject to exfiltration, and if it is less than one it is de-pressurized and thus subject to infiltration.

$M_{\text {fresh }}$ is the fresh air mass actually injected during a complete cycle, while $M_{\text {fresh, max }}$ is the maximal fresh air mass that can be injected considering a constant flow rate. This indicator cannot be greater than 1.

\subsection{Comparison of strategies}

The above presented strategies have been compared by considering the supply conditions given in Table 4 .

In the following simulations, these indoor and outdoor conditions are kept constant during the whole simulation time. However, additional simulations were made with different fresh air temperatures. These results are consistent and available in the annexes. The simulation results are summed up in Table 5.

For the simulation of the balance adjustment and pre-heating by mixture of indoor and outdoor air methods, different implementations could take place. It may be decided to vary only one of the two flow rates. In other words, only one air flow can be increased or decreased (i.e. indoor or outdoor air). Alternatively, both rates can vary simultaneously. For instance, the outdoor air flow rate can be decreased and the indoor air flow rate can be increased at the same time (most important is to ensure an unbalancing of the two flow rates). Here, only the fresh air flow rate has been decreased, in order to obtain a wall temperature of $0.5^{\circ} \mathrm{C}$ at the exhaust of the heat exchanger's outdoor air side. Concerning the pre-heating by mixture of indoor and outdoor air method, the stale air going through the exchanger is kept constant. However, the fresh air fan imposes, in addition to $\dot{V}_{\text {fresh,max }}$, a stale air flow rate on the fresh air side of the heat exchanger. The aim, as stated above, is to reach a wall temperature of $0.5^{\circ} \mathrm{C}$ at the exhaust of the heat exchanger.

As shown in Table 5 , the strategy presenting the best $\Omega_{\text {device }}$ is the balance adjustment. However, this technique implies a large over-pressurization of the building and results in the lowest air renewal quality of all. On the other hand, the electrical preheating presents a perfect balance and maximum air renewal but the $\Omega_{\text {device }}$ is very low (about 1 ). In between, the remaining strategies show relatively good $\Omega_{\text {device }}$ with acceptable pressure balance and air renewal. Based on the three defined criteria, they seem to be the best trade-off. However, another crucial aspect is the practical implementation of these techniques. 
Table 5

Simulation results for the different frost control strategies.

\begin{tabular}{|c|c|c|c|c|c|c|c|}
\hline \multicolumn{2}{|l|}{ Strategy } & \multirow{2}{*}{$\begin{array}{l}\text { Frosting time } \\
\text { [s] } \\
7200\end{array}$} & \multirow{2}{*}{$\begin{array}{l}\text { Defrosting } \\
\text { time [s] } \\
240\end{array}$} & \multirow{2}{*}{$\begin{array}{l}\text { Cycle time [s] } \\
7440\end{array}$} & \multirow{2}{*}{$\begin{array}{l}\Omega_{\text {device }}[-] \\
10.4\end{array}$} & \multirow{2}{*}{$\begin{array}{l}\varphi_{\text {balance }}[-] \\
1.03\end{array}$} & \multirow{2}{*}{$\begin{array}{l}\varphi_{\text {renewal }}[-] \\
0.97\end{array}$} \\
\hline$\dot{V}$ constant & $\begin{array}{l}\text { Supply air } \\
\text { outdoor fan } \\
\text { shutoff }\end{array}$ & & & & & & \\
\hline & $\begin{array}{l}\text { Indoor air } \\
\text { recirculation }\end{array}$ & 7200 & 155 & 7355 & 10.5 & 1.00 & 0.98 \\
\hline \multirow[t]{2}{*}{$\dot{W}_{f a n}$ constant } & $\begin{array}{l}\text { Supply air } \\
\text { outdoor fan } \\
\text { shutoff }\end{array}$ & 7200 & 118 & 7318 & 10.8 & 0.91 & 0.98 \\
\hline & $\begin{array}{l}\text { Indoor air } \\
\text { recirculation }\end{array}$ & 7200 & 102 & 7302 & 10.8 & 0.89 & 0.99 \\
\hline \multicolumn{2}{|c|}{ Balance adjustment } & 0 & 0 & 0 & 11.0 & 2.73 & 0.37 \\
\hline \multicolumn{2}{|c|}{ Electrical preheating } & 0 & 0 & 0 & 1.1 & 1.00 & 1.00 \\
\hline \multicolumn{2}{|c|}{$\begin{array}{l}\text { Pre-heating by mixture of indoor and } \\
\text { outdoor air }\end{array}$} & 0 & 0 & 0 & 8.0 & 1.00 & 1.00 \\
\hline
\end{tabular}

\section{Discussion}

The numerical simulations showed good results in the framework of a single room ventilation unit exchanger. However, this model could be extended to other applications dealing with this kind of exchanger, typically for centralized ventilation with heat recovery or cooling coils.

From the authors' own experience and extended exchanges with an industrial sector specialist, various aspects pertaining to practical implementation came to light and are discussed hereafter. These are specifically valid for single room ventilation units.

The constant volumetric flow rate strategy requires measurement of the flow rate to control the speed of the fan. Different measurement techniques exist but are difficult to implement within compact units with ducts of a short length. Furthermore, the fan speed must be able to vary in a continuous way. This strategy with recirculation has the same requirement, with an additional recirculation loop, and necessitates specific valves. Concerning the constant electric fan power, the rotational speed stays constant, which means that no additional measurement is required. This solution seems to be simpler. With the recirculation, the requirement is the same as for its counterpart with constant volumetric flow rate. For these four strategies, a criterion on the maximum acceptable frost level has to be implemented, as well as an indicator allowing evaluation of the moment when the defrost phase is over.

Concerning the balance adjustment method, only one measurement should be necessary: the wall temperature at the exhaust of the indoor air stream. However, by knowing the outdoor temperature and using a security factor, this measure is not compulsory, and the control strategy is even easier. This allows a controller to adjust the fan speed to either increase or decrease the mass flow rate, depending on the conditions. For the electrical preheating, a resistance needs to be added to the device. The power injected must be controlled in order to avoid either frost or unnecessary electrical consumption. The last method developed in this paper is the mixture of fresh and stale air. It only needs an appropriate valve and a controller driving this latter in function of the wall temperature at the exhaust of the stale air stream.

The implementation difficulty of each method must be kept in mind while analysing Table 4. From the authors' point of view, the method with $\dot{W}_{\text {fan }}$ constant and no recirculation should be highlighted as the best trade-off.

In the present analysis, the electrical energy was not converted into primary energy. Taking this aspect into account will not change the ranking between the different strategies, only the absolute values of the energy criteria $\Omega_{\text {device }}$. Moreover, the frosting time of $7200 \mathrm{~s}$ was arbitrarily chosen for the presented simula- tions. To have an efficient system, an optimization process should be implemented which defines the best frosting time before starting the defrost. Such a process would allow an increase in the global performance of the ventilation system. This optimized frosting time may vary depending on the chosen strategy.

\section{Conclusions}

The aim of this paper was to investigate the impact of the frost layer on the hydraulic and thermal performance of an air-to-air heat exchanger dedicated to single room ventilation with heat recovery. The first step was to adapt a known "two-zone" model by adding a third zone (so-called frost zone). To do so, a frost growth model was first developed. This latter was based on several publications and validated by means of experimental data from scientific literature. The model was validated by comparing the frost layer thickness evolution under several operating conditions.

Considering the behaviour of a heat exchanger under frosting conditions, experimental investigations were carried out on a Uflow heat exchanger with corrugations of $30^{\circ}$ in the central part. The first part of the experimental investigations aimed at confirming the validity of the "two-zone" heat exchanger model, but on a heat exchanger presenting a different geometry. Investigations under frosting conditions were then performed, and analysis of the experimental data was achieved. The conclusions to be drawn concern the influence of the humidity: tests performed under air supply conditions with a high relative humidity show an evolution different from the one predicted by the model. This is due to the influence of the condensates flowing out of the heat exchanger and perturbing the theoretical formation of frost. This influence is reduced when the wet part is smaller.

Regarding the thermal performance, the thickness of the frost deteriorates the total heat flow rate. This is due to the additional thermal resistance introduced by the frost. The model gives a satisfying trend, even if the proportion of sensible and latent heat transfer rates is misbalanced. The model is then able to give satisfying trend predictions for hydraulic and thermal performances within a time frame of two hours under frost conditions.

As the model has been judged valid, several methods under frosting conditions have been presented. Ease of application has been considered and discussed in each case, especially in the case of the development of single room ventilation with heat recovery. All methods were then compared by means of three coefficients: an energy performance coefficient, a coefficient showing the potential pressure imbalance between the inside and the outside of the building and finally a coefficient showing the air renewal performance. The practical implementation aspects of the strategies 
were discussed to complete the global analysis of the different methods.

The different lessons learned are:

- The two-zone model (dry and wet parts) was validated with an exchanger presenting a different geometry than the one investigated in the past.

- Despite difficulty to ensure accuracy due to the phenomena complexity, a new three-zone model has been developed and validated with experimental tests. The trends were good and judged acceptable to perform analyses on frost control strategies.

- Different strategies dealing with frost conditions were presented and compared on the basis of three different criteria. The choice of strategy must be made from a trade-off between the energy considerations, the air renewal, the de/overpressurization of the building and the practical implementation. In the authors' opinion, the best strategy would be the one with $\dot{W}_{\text {fan }}$ constant and no recirculation.

\section{Funding}

This work was supported by the Walloon Region and the Pole Mecatech [convention 7711].

\section{Conflicts of Interest}

We wish to confirm that there are no known conflicts of interest associated with this publication and there has been no significant financial support for this work that could have influenced its outcome.

\section{Appendix. strategy performance variation with different fresh air temperatures at the supply of the heat exchanger}

The different figures shown in this appendix reveal the performance of the different strategies in the exact same conditions as described in the main text (same frosting time), except for $T_{s u}$, fresh .

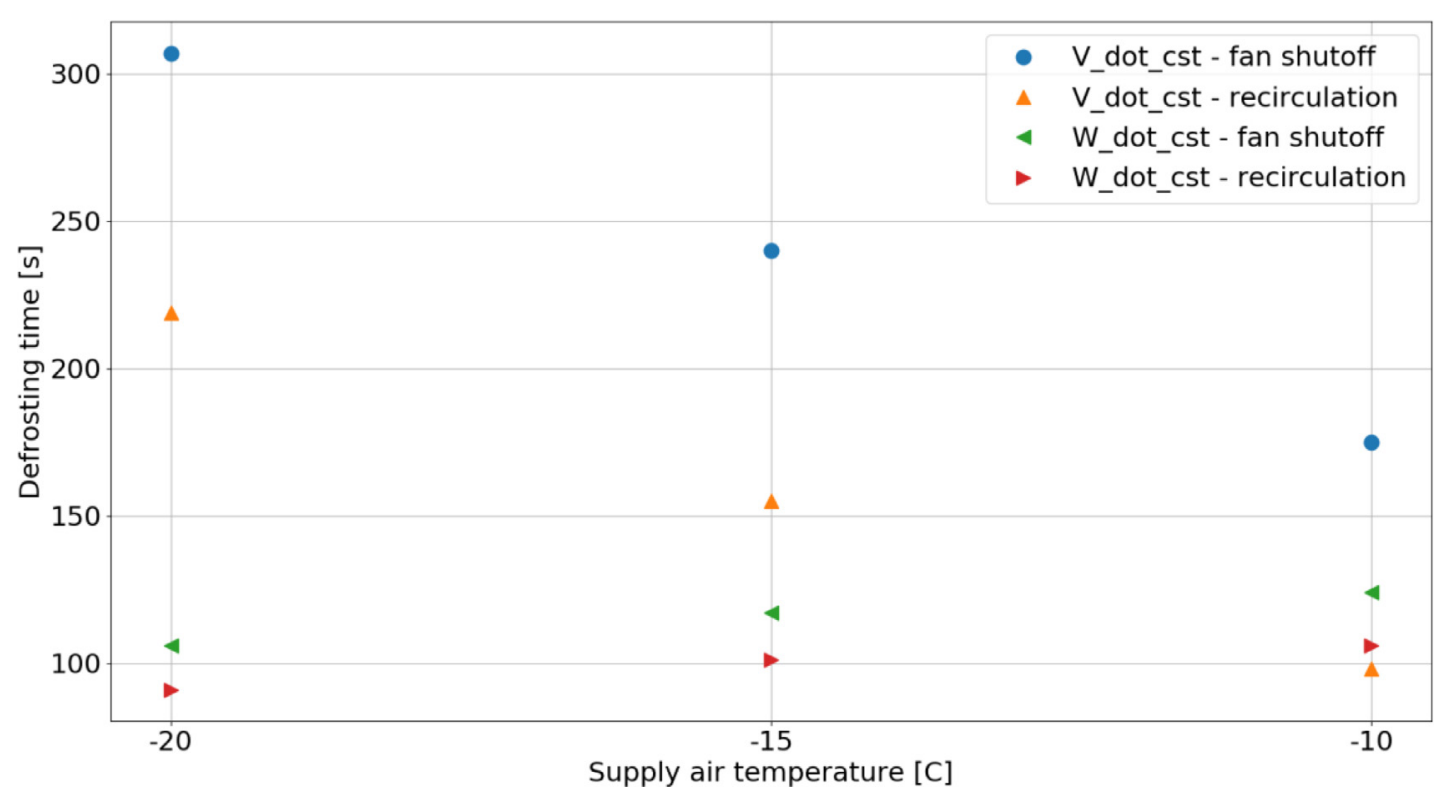

Fig. 21. Defrosting time for different strategies and fresh air supply temperature

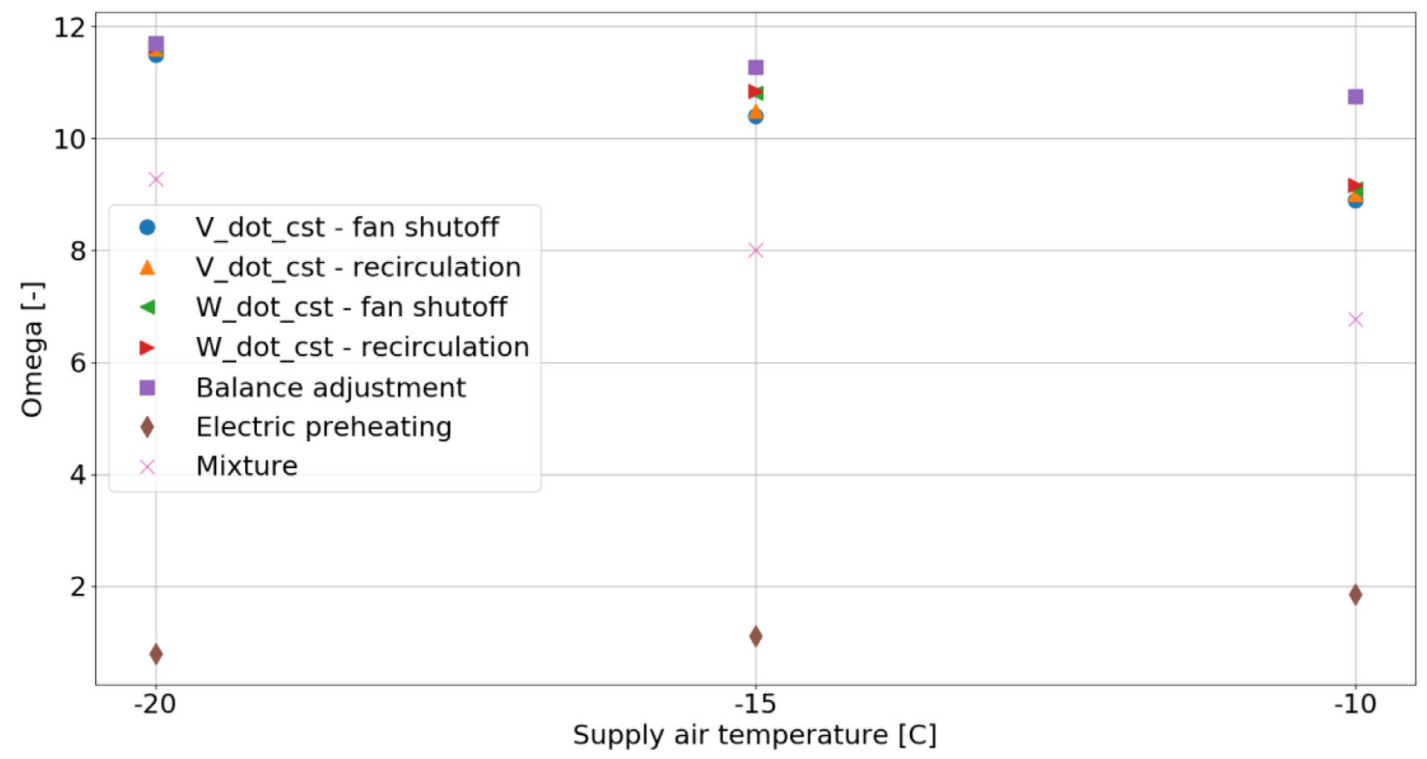

Fig. 22. $\Omega_{\text {device }}$ for different strategies and fresh air supply temperature. 


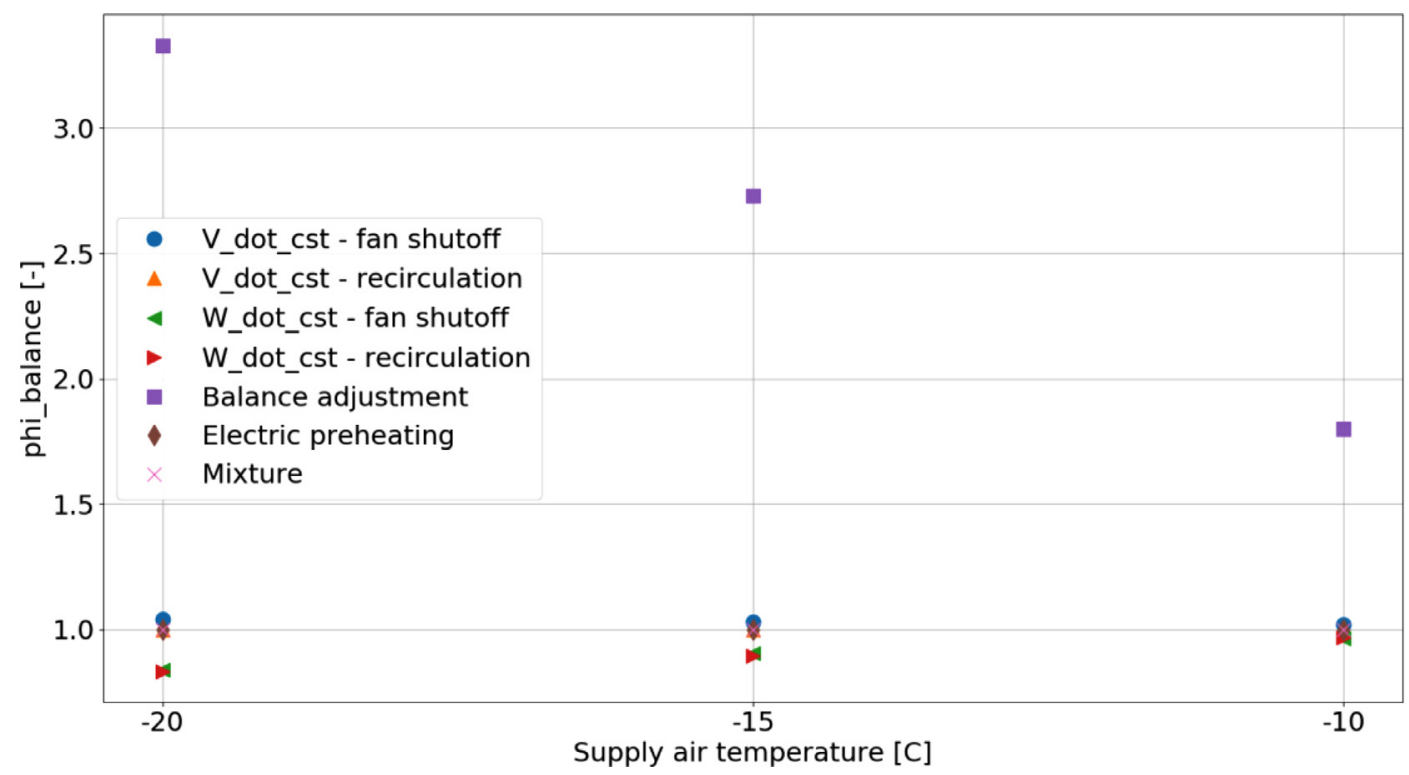

Fig. 23. $\varphi_{\text {balance }}$ for different strategies and fresh air supply temperature.

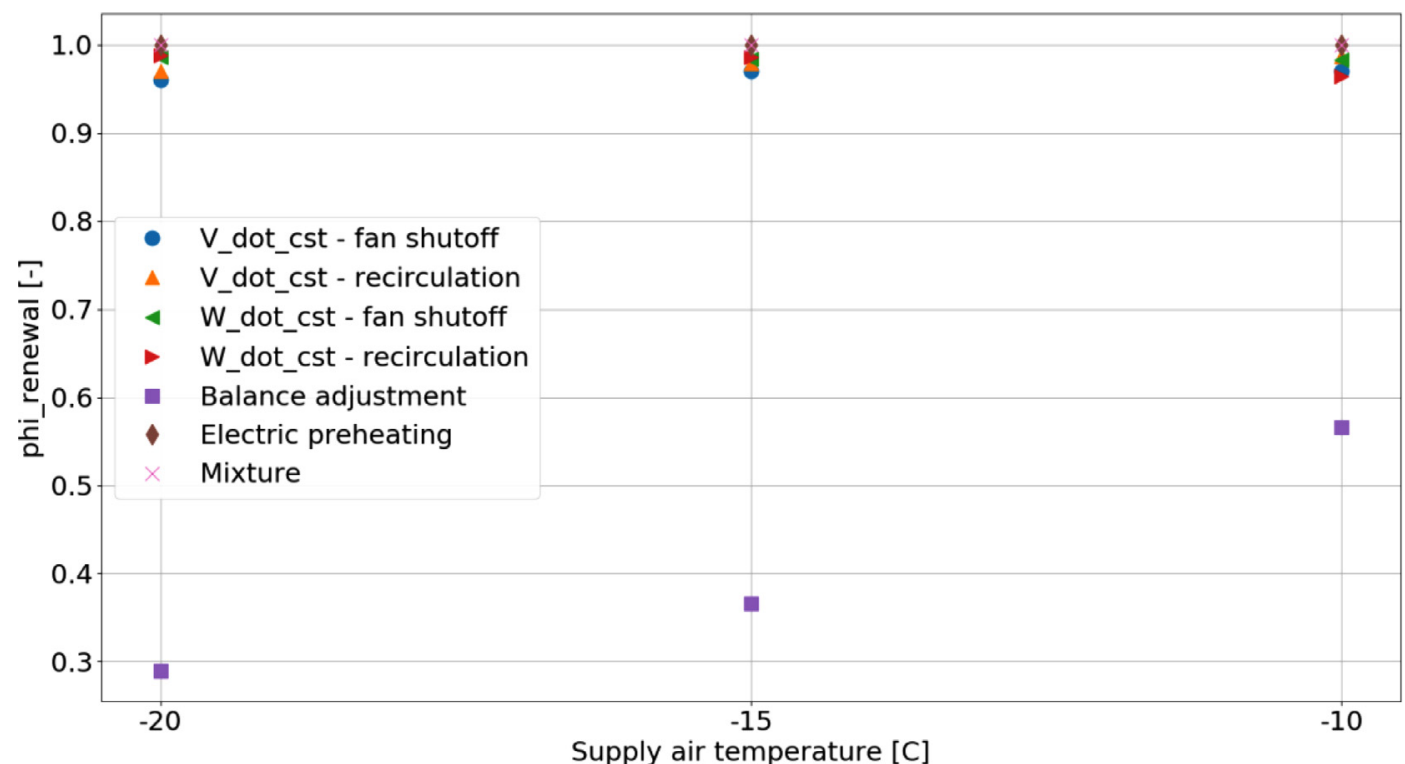

Fig. 24. $\varphi_{\text {balance }}$ for different strategies and fresh air supply temperature.

The fresh air supply temperature varied from $-20^{\circ} \mathrm{C}$ to $-10^{\circ} \mathrm{C}$, to deduce the impact of this temperature on each strategy.

\section{References}

[1] Z. Ayub, Plate heat exchanger literature survey and new heat transfer and pressure drop correlations for refrigerant evaporators, Heat Transf. Eng. 24 (5) (2003) 3-16.

[2] R. Bantle, Prediction and control of frost formation in air-to-air heat exchanger Master thesis, University of Sakatchewan, 1987.

[3] R. Bantle, E. Barber, R. Besant, A Mathematical Model of a Plate Type Airto-Air Heat Exchanger Operating Under Frost Forming Conditions, University of Saskatchewan, 1987.

[4] R. Bantle, E. Barber, E. Moysey, S. Sokhansanj, Maximizing heat recovery in air-to-air heat exchanger operating under frosting conditions, Presentation to the Canadian Society of Agricultural Engineering, Montreal, 1987.

[5] C. Beattie, P. Fazio, R. Zmeureanu, J. Rao, Experimental study of air-to-air heat exchangers for use in arctic, Appl. Therm. Eng. 129 (2018) 1281-1291.

[6] H. Chen, L. Thomas, R. Besant, Fan supplied heat exchanger performance under frosting, Int. J. Refrig. 26 (1) (2003) 140-149.

[7] C. Cheng, Y.-C. Cheng, Predictions of frost growth on a cold plate in atmospheric air, Int. Comm. Heat Mass Transf. 28 (7) (2001) 953-962.
[8] Eurostat, Consumption of energy, 2018. Retrieved June 26, 2018, from http://ec.europa.eu/eurostat/statistics-explained/index.php?title=Consumption of_energy\#End-users.

[9] W. Fisk, K. Archer, D. Hekmat, Onset of freezing in residential air-to-air heat, ASHRAE Trans. 91 (1984) 145-158.

[10] W. Fisk, R. Chant, K. Archer, D. Hekmat, F. Offerman, B. Pedersen, Performance of residential air-to-air heat exchangers during freezing and periodic defrosts, ASHRAE Trans. 91 (1985) 159-172.

[11] W. Frisk, R. Chant, K. Archer, D. Hekmat, F. Offerman, B. Pedersen, Performance of residential air-to-air heat exchangers during freezing and periodic defrosts, ASHRAE Trans. 91 (1985) 159-172.

[12] S. Gendebien, Contributions to the development of a single room ventilation unit with heat recovery $P h D$ Thesis, 2014

[13] S. Gendebien, S. Bertagnolio, V. Lemort, Investigation on a ventilation heat recovery exchanger: modeling and experimental validation in dry and partially wet conditions, Energy Build. 62 (2013) 176-189.

[14] S. Gendebien, J. Martens, V. Lemort, Designing an air-to-air heat exchanger dedicated to single room ventilation with heat recovery, Build. Simul. 11 (2018) 103-113.

[15] C. Händel, Ventilation with heat recovery, Rheva J. (2001).

[16] Y. Hayashi, A. Aoki, S. Adachi, K. Hori, Study of frost properties correlating with frost, J. Heat Transf. 99 (1977) 239-245.

[17] C. Hermes, R. Piucco, J. Barbosa, C. Melo, A study of frost growth and densification on flat surfaces, Exp. Therm. Fluid Sci. 33 (2) (2009) 371-379. 
[18] A. Jedlikowski, S. Anisimov, Analysis of the frost formation and freeze protection with bypass for cross-flow recuperators, Appl. Therm. Eng. 116 (2017) 731-765.

[19] A. Jedlikowski, S. Anisimov, J. Danielewicz, M. Karpuk, D. Pandelidis, Frost formation and freeze protection with bypass for counter-flow, Int. J. Heat Mass Transf. 108 (2017) 585-613.

[20] M. Justo Alonso, L. Peng, H. Mathisen, G. Ge, C. Simonson, Review of heat/energy recovery exchangers for use in ZEBs in cold climate countries, Build. Environ. 84 (2015) 228-237.

[21] Lee, Kim, Lee, A one-dimensional model for frost formation on a cold flat surface, Int. J. Heat Mass Transf. 40 (18) (1997) 4359-4365.

[22] A. Léoni, M. Mondot, F. Durier, R. Revellin, P. Haberschill, State-of-the-art review of frost deposition on flat surfaces, Elsevier 68 (2016) 198-217.

[23] Y. Mercadier, T. Duong, F. Lagace, Dynamic performance of a cross flow heat recovery, in: Proceedings of the fourth international symposium on, Hanover, 1993, pp. 113-121.

[24] B. Na, R. Webb, A fundamental understanding of factors affecting frost nucleation, Int. J. Heat Mass Transf. 46 (20) (2003) 3797-3808.

[25] T. Nielsen, J. Kragh, S. Svendsen, Evaluation of a dynamic model for a cold climate counter, in: Proceedings of the 8th Symposium on Building Physics in the Nordic, Copenhagen, 2008.

[26] T. Nielsen, J. Kragh, S. Svendsen, Evaluation of a dynamic model for a cold climate counter flow air-to-air heat exchanger, in: Proceedings of the 8th Symposium on Building Physics in the Nordic Countries, Copenhagen, 2008.
[27] E. Philips, R. Chant, B. Bradley, F. D.R, An investigation of freezing control strategies for residential air-to-air heat exchangers, ASHRAE Technical Committee, Atlanta, 1989

[28] M. Rafati Nasr, M. Kassai, G.S.-J. Gaoming, Evaluation of defrosting methods for air-to-air heat/energy exchangers on energy consumption of ventilation, Appl. Energy 151 (2015) 32-40.

[29] J. Rose, J. Rammer Nielsen, S. Svendsen, Quasi-steady-state model of a counter-flow air-to-air heat-exchanger with phase change, Appl. Energy 85 (5) (2008) 312-325.

[30] C.-A. Roulet, F. Heidt, F. Foradini, M.-C. Pibiri, Real heat recovery with air handling units, Energy Build. 33 (5) (2001) 495-502.

[31] W. Shurcliff, Air-to-air heat exchangers for houses, An. Rev. Energy 13 (1988) $1-22$.

[32] D. Silva, Hermes, Melo, Experimental study of frost accumulation on fansupplied tube-fin evaporators, International Refrigeration and Air Conditioning Conference, Purdue, 2010.

[33] I. Standard, ISO 5167. Measurement of Fluid Flow by Means of Pressure Differential Devices Inserted in Circular Cross-Section Conduits Running Full, First edition, Internal Organisation for Standardization, 1980.

[34] A.S. Wanniarachchi, U. Ratnam, B.E. Tilton, K. Dutta-Roy, in: Approximate Correlations for 30th National Heat Transfer Conference, 314, New York, 1995, pp. 145-151.

[35] Zhong Xia, Hrnjak, Jacobi, Frost, defrost, refrost, and its impact on the air-side thermalhydraulic, Int. J. Refrig. 29 (2006) 1066-1079. 